\title{
APROXIMACIÓN AL AGUSTINO FRAY ANTONIO JOSÉ DE ALBA (1735-1813), MAESTRO DE MÉLENDEZ VALDÉS
}

\author{
Concerning the Augustinian Friar Antonio José de Alba \\ (1735-1813), Teacher of Meléndez Valdés
}

\author{
Antonio ASTORGANO ABAJO \\ Real Academia de Extremadura. Correspondiente. \\ astorgano1950@gmail.com
}

Fecha de recepción: 2/12/2016

Fecha de aceptación definitiva: 10/05/2017

RESUMEN: Desde 1772 Meléndez Valdés estuvo ligado al convento de San Agustín y al colegio de San Guillermo, ambos de los agustinos calzados de Salamanca, donde contó con amigos aficionados a la poesía, como los frailes Diego González (prior), Juan Fernández de Rojas, Andrés del Corral, Pedro Madariaga y Antonio José de Alba. Durante el quinquenio de 1775-1780 tuvieron una tertulia en la celda del prior Diego González. Allí establecieron una amistad permanente, basada en los mismos gustos poéticos e ideológicos cercanos al jansenismo. En el presente trabajo se trata de esbozar los rasgos generales de la biografía del maestro Antonio José de Alba y sus relaciones con Meléndez.

Palabras clave: Antonio José de Alba; agustinos calzados; Universidad de Salamanca; Meléndez Valdés; Humanidades.

ABSTRACT: From 1772 Meléndez Valdes had links with the convent-school of St. Augustine in Salamanca, a community of Agustinian monks, where he had friends enthusiastic about poetry such as Diego González (Prior), Juan Fernández de Rojas, Andrés del Corral, Pedro Madariaga and Antonio José de Alba. During the period 1775-1780 they met regularly in the cell of the Prior Diego González. There grew a 
firm friendship, based on the same poetic and ideological tastes which had affinities with Jansenism. The present study attempts to outline the essential biographical characteristics of Antonio José de Alba and his relationship with Meléndez.

Key words: Antonio José de Alba; Augustinian monks; University of Salamanca; Meléndez Valdés; the Humanities.

\section{INTRODUCCIÓN}

Para determinar el ambiente ideológico que se respiraba en el convento de los agustinos calzados de Salamanca durante la Ilustración, lógicamente no procede que nos detengamos en biografiar a cada uno del cuarto de millar de religiosos que pasaron por él en la década de 1770-1780, pero es interesante fijarse en el maestro Antonio José de Alba, sucesivamente profesor de Filosofía, de Prima de Humanidades y de Teología, por su ideología claramente ilustrada, como se evidencia en sus intervenciones en los claustros universitarios, capitaneando un grupo en el que se incluían los extremeños Juan Justo García ${ }^{1}$ y Juan Meléndez Valdés. Con la perspectiva histórica que hoy tenemos, no es aventurado afirmar que en la década 1770-1780, no sólo se aplicó con dificultades el plan de estudios de 1771, sino que en la confusión socioacadémica de los bandos enfrentados en el claustro universitario se estaba gestando el germen del primer Liberalismo español.

Sabemos muy poco de la vida del madrileño Antonio José Ramón de Alba y Ayuste, amigo y maestro de Meléndez, nacido el 17 de enero de 1735 en la parroquia de Santa Cruz:

En la Iglesia parroquial de Santa Cruz de esta Villa de Madrid en el día 18 de enero del año de 1735, yo don Francisco Cangas, teniente cura de dicha parroquia, bapticé solemnemente un niño que nació en 17 de dicho mes y año. Púsele por nombre Antonio José Ramón, hijo de Pedro de Alba, natural del lugar de Resellonas [actual Braña de Resielles], parroquia de [Santa María de] Soto de Luiña, obispado de Oviedo, y de Juana de Aiuste, su legítima mujer, natural de la ciudad de Guadalajara, de este arzobispado. Viven en la calle de la Compañía [actual calle Estudios], casas del marqués de Rivas. Fue su padrino, digo madrina, doña María Ontañón, mi parroquiana. Advertile el parentesco espiritual y la obligación de enseñarle la doctrina cristiana, y lo firmé. Don Francisco de Cangas².

1. Robledo, Ricardo. "Juan Justo García». En Lama, José María (ed.). Los primeros liberales españoles. La aportación de Extremadura, 1810-1854. Badajoz: Diputación Provincial de Badajoz, 2012, pp. 27-48. El convento agustino dieciochesco ha sido estudiado específicamente por ASTORGANO, A. "Poesía y jansenismo en el convento de los agustinos calzados de Salamanca en tiempos de Meléndez Valdés». Revista de Estudios Extremeños, 2016, 77.1, pp. 147-208.

2. Archivo Histórico Diocesano de Madrid, Parroquia de Santa Cruz, Libro de bautismos 25 (1729-1736), f. 325r. 
Gregorio de Santiago Vela, historiador de referencia de la orden de los agustinos calzados, confiesa que no posee datos posteriores al 23 de septiembre de 1791. A diferencia de las amplias páginas dedicadas a otros agustinos, Vela literalmente le dedica estas líneas:

Alba (Fr. Antonio José de). Natural de Madrid é hijo de Pedro de Alba y Juana Ayuste, en consulta celebrada en San Felipe el Real á 11 de Julio de 1749 fue admitido como postulante al santo hábito, y cumplido después el año de noviciado, emitió los votos religiosos el 18 de enero de 1751. Al margen de su profesión se escribió esta nota: «Es graduado de Salamanca y mozo muy hábil» ${ }^{3}$. Por comisión del Rmo. P. General de la Orden presidió el Capítulo de la Provincia de Castilla, celebrado el 23 de abril de 1779. Con fecha 23 de septiembre de 1791 aparece en un escrito como Asistente General de las Provincias de España é Indias. No poseemos datos posteriores á esta última fecha. Sus títulos científicos pueden verse expresados en la portada de la oración fúnebre que publicó ${ }^{4}$.

A continuación Santiago Vela se limita a citar su única obra publicada conocida, El Filósofo. Oración fúnebre (1780), que Alba predicó, en nombre de la Universidad, a la buena memoria del franciscano observante y moderante de la Academia de Teología fray Manuel Fernández . También subraya su colaboración con el agustino Francisco Méndez, a quien Alba le remitió apuntes para la vida de Fr. Luis de León, y copias de sus obras manuscritas conservadas en Salamanca ${ }^{6}$.

La personalidad del maestro Alba ha llegado hasta nosotros envuelta en un halo de misterio, a pesar de que fue un magnífico pedagogo, según testimonio

3. Su profesión se encuentra en AHN, Códices y Cartularios, Libro VI de profesiones del convento de agustinos ermitaños de San Felipe el Real de Madrid, Códice L. 206, f. 260r.

4. Santiago Vela, Gregorio de. Ensayo de una Biblioteca Ibero-Americana de la Orden de San Agustín por el P. Gregorio de Santiago Vela, de la Provincia del Santísimo Nombre de Jesús de Filipinas. Obra basada en el catalogo bio-bibliográfico agustiniano del P. Bonifacio Moral, ex provincial de la Matritense. Publicase a expensas de la expresada Provincia de Filipinas, vol. I, letras A-Ce. Madrid: Imprenta del Asilo de Huérfanos del Sagrado Corazón de Jesús, 1915, pp. 104-105.

5. AlBA, Antonio José. El Filósofo / Oración fúnebre, / que en las exequias, / que celebró la Universidad de Salamanca / a la buena memoria de su ilustre bijo / el Rmo. Padre Maestro / Fr. Manuel Fernández / del Orden del Seráfico P. S. Francisco, / Custodio de su Apostólica Provincia de Santiago, / Guardián del Convento grande de dicha Ciudad, Doctor / Theologo, y Moderante de la Academia de Theólogos / de esta Universidad / dixo el RR. P. Mro. Fr. Antonio Josef de Alva, / del orden de San Agustín, Difinidor, y Prefecto General / de los Estudios de su Provincia de Castilla, Doctor/Theólogo, y Cathedrático de Regencia de Theología / de dicha Universidad. / Impresa en Salamanca en la oficina de la Santa Cruz / por Domingo Casero, pp. 40, en $4 .^{\circ} .7$ hojas preliminares sin foliar: dos lemas de San Pablo y de San Clemente Alejandrino; dos Dictámenes del licenciado don Miguel Antonio Salgado, canónigo de la Santa Iglesia Catedral de Salamanca (29 de enero de 1780) y del doctor frey don Domingo Granda Rivero, colegial huésped y regente de cánones del Militar Colegio del orden de Alcántara (1 de febrero). Aprobación del licenciado don Rafael Sánchez Barriga, presbítero, catedrático de Santo Tomás (12 de febrero). Imprimátur del licenciado don Antonio Piñuela. Ejemplar en BNE, signatura VC/3494/20 (en línea: http:// bdh-rd.bne.es/viewer.vm?id=0000085728\&page=1).

6. Santiago Vela. Ensayo de una Biblioteca Ibero-Americana, cit., vol. I, pp. 104-105. 
de sus discípulos (incluido Meléndez Valdés), luchador por implantar la filosofía moderna en la Universidad de Salamanca y cercano al nuevo e ilustrado Colegio de Filosofía que impulsaban Juan Justo García, Ramón de Salas, Miguel Martel y Meléndez Valdés, entre otros. Además de hombre de pensamiento, Alba fue un buen y pragmático gestor, como demostró al dirigir la Universidad de Salamanca, en calidad de vicerrector con funciones de rector, durante los difíciles años de la ocupación napoleónica (1809-1812).

No es de extrañar que, excepto la oración fúnebre El Filósofo, no haya llegado a nosotros ningún escrito del P. Alba, pues, a excepción del padre Pedro Manso (fallecido en 1736), el catedrático agustino más conocido en la Salamanca del siglo XVIII, que publicó todas sus obras, sólo otros tres catedráticos agustinos editaron algunos de sus escritos. Los demás dejaron manuscritos en el convento de San Agustín de Salamanca, que fue saqueado y destruido por los franceses el 17 de mayo de $1812^{7}$. De esta manera tan trágica se desvaneció el que llegasen a nosotros los manuscritos que el maestro Alba leía en clase y los alumnos copiaban con gran fidelidad. A pesar de todo, por su trayectoria vital y por lo que se puede deducir de su El Filósofo y las censuras que emitió, como a la "Lógica" de Díaz de Gamarra ${ }^{8}$, Alba fue uno de los frailes más abiertos al pensamiento europeo ilustrado, en consonancia con la corriente ideológica agustiniana en la escuela salmantina ${ }^{9}$, que durante el siglo XVIII era de tendencias filojansenistas, siguiendo a sus maestros Enrique Noris (1631-1704) ${ }^{10}$ y Juan Lorenzo Berti (1696-1766).

Del aprecio que Alba tenía dentro de su orden, alguno de sus correligionarios supo calibrar la personalidad del «mozo» Antonio José cuando escribió, después de 1763, que fue cuando recibió los primeros grados en la Universidad de Salamanca, al margen del asiento de la profesión la citada nota: "Es mozo muy hábil»" ${ }^{11}$ Por su parte, Esperabé de Arteaga resume el carisma del maestro Alba: «Fue hombre de mucha ciencia y gran prestigio tanto en la Universidad como dentro de la Orden ${ }^{12}$.

7. ZAONERO, Joaquín. Libro de noticias de Salamanca que empieza a regir el año de 1796 hasta 1812. Edición crítica de Ricardo Robledo. Salamanca: Librería Cervantes, 1998, pp. 91-92.

8. MuÑoz Delgado, Vicente. "La Universidad de Salamanca (1778) y los Elementa recentioris Philosophiae (México 1774) de Juan Benito Díaz de Gamarra y Dávalos». Cuadernos Salmantinos de Filosofía, 1981, 8, pp. 149-174; "Los agustinos y la Filosofía en México durante el siglo xvI". Ciudad de Dios: Revista Agustiniana, 1992, 205 (n. ${ }^{\circ} 2-3$ ), pp. 411-462.

9. Domínguez CARRETERo, Eloy. "La escuela teológica agustiniana de Salamanca». La Ciudad de Dios, Revista Agustiniana, 1956, 168, pp. 638-685.

10. MARTínEZ, Agustín M. Introducción a la teología del cardenal Enrique Noris, agustino (16311704). Santiago de Chile: Imp. Lathrop, 1946; Wernicke, Michael Klaus. Kardinal Enrico Noris und siene Verteidigung Augustins. Würzburg: Augustinus-Verlag, 1973.

11. Santiago Vela. Ensayo de una Biblioteca Ibero-Americana..., cit., vol. I, pp. 104-105.

12. Esperabé de Arteaga, Enrique. Historia pragmática e interna de la Universidad de Salamanca. Salamanca: Imprenta y Librería de Francisco Núñez, 1917, vol. II, p. 722. 


\section{Biografía de FRAY ANTONiO DE AlBa, a TRAVÉS DE lOS CURRÍCUla DE SUS OPOSICIONES A CÁTEDRAS DE la Universidad DE SALAMANCA}

Una primera fuente biográfica, segura pero elemental, son los Libros de procesos de cátedras, a muchas de las cuales opositó. Sólo cotejaremos los datos de un par de ellas que consideramos significativas, por el rango de la oposición y por ser de las últimas. A lo largo de 1786 Alba participó en la oposición a la cátedra de Vísperas de Teología, vacante por fallecimiento del reverendo padre maestro don Gaspar Sanz. Se remitió al Consejo de Castilla el informe del tribunal y del rector el 10 de junio de 1786. La relación de méritos presentada por Antonio José de Alba, que apostillamos cronológicamente entre paréntesis, fue la siguiente:

Maestro fray Antonio José de Alba, del orden del gran padre San Agustín, catedrático de regencia de teología de la Universidad de Salamanca por merced de su majestad (que Dios guarde) a consulta de su real y supremo Consejo, desde 24 de octubre de 1778, en que tomó posesión de ella, tiene los títulos, grados y ejercicios literarios siguientes. Primeramente consta tener probados 35 [36, corrección manuscrita] años de estudios mayores en las facultades de artes y teología [por lo tanto empezó a estudiar los tres años de Filosofía en el Colegio agustino Doña María de Aragón en 1751]. Consta haber sustentado 11 actos, ocho en teología y tres en artes: ocho de ellos fueron mayores y los tres menores: de los de teología, dos fueron defendidos en esta Universidad por su religión. Leyó dos veces de oposición con puntos de 24 horas [probablemente en Valladolid en 1759, cuando empezó la docencia], siendo cada lección de hora, sufriendo dos horas de argumentos de los maestros de su religión, jueces para dar las lecturas de artes. Leyó artes y teología en Valladolid [en el convento 1759-1762] y Salamanca [Teología en el convento 1763-i?], arguyendo y replicando dentro y fuera de su religión, según la práctica de su orden, y dichas universidades. Ha presidido 19 [20 corrección manuscrita] actos mayores, y cinco menores; 12 [13, corrección manuscrita] en la facultad de teología y tres en la de artes; y de los de teología nueve [10, corrección manuscrita] mayores y nueve [10, corrección manuscrita] menores presididos pro Universitate en este estudio general. Recibió en esta Universidad de Salamanca los grados de bachiller en artes y teología en el 15 de septiembre de 1763. Tubo las funciones de Quodlibetos para el grado de licenciado. Recibió el grado de licenciado por esta Universidad el día 12 de diciembre de dicho año 1763, habiendo precedido dos lecciones de hora, una de repetición y otra la noche del riguroso examen en la capilla de Santa Bárbara, en el que fue aprobado nemine discrepante. Recibió asimismo el grado de doctor por esta Universidad con la solemnidad acostumbrada el día 14 de febrero de 1764. Leyó 10 [11, corrección manuscrita] veces de oposición, empleando en cada lección una hora, con puntos de 24 , tres a las cátedras de regencia de artes, tres a la de vísperas de teología [una en 1781] con la vacante [1786], una a la de filosofía natural [1770-72], dos a la de curso teológico y tres [cuatro, corrección manuscrita] a la de lugares teológicos [Alba opositará a esta cátedra en 1784, 1786 y 1797, que sepamos], sufriendo una hora de argumentos de sus contrincantes, a los que igualmente arguyó siempre que le tocó por turno. Fue siete años [1772-78] sustituto de la cátedra de prima de humanidad por nombramiento del claustro pleno de esta Universidad y aprobación del Consejo de Castilla [noviembre de 1772]. Ha leído también a la cátedra de prima 
de humanidad [1770-72, no llegó a consultarse], en cuya facultad ha presidido tres actos menores y las sabatinas que le han tocado por turno en cumplimiento del nuevo plan [de Estudios de 1771]. Tiene el especial mérito de haber defendido con puntos de 24 horas una conclusión para que dos opositores completasen los ejercicios, según previene el nuevo plan. Es prefecto de los estudios de su provincia [agustinos calzados] por nombramiento especial de su general ${ }^{13}$.

Lógicamente el currículo presentado en la oposición de la cátedra de Lugares Teológicos de ese mismo año 1786, vacante por ascenso del maestro Antonio Muñoz a la de Vísperas, otorgada al maestro José de la Oliva en 30 de agosto de 1787, es casi idéntico al anterior. Esta oposición tiene cierta importancia, porque también concurren el agustino José Díaz y Diego Muñoz Torrero, futuro presidente de las Cortes de Cádiz ${ }^{14}$.

Alba volvió a presentarse en 1791 a la cátedra de Prima de Teología que ganó el maestro fray Antonio Muñoz, de los clérigos menores, vacante por muerte del cisterciense fray Basilio de Mendoza. Se remitió el expediente desde la Universidad al Consejo de Castilla el 2 de julio de 1791, quien la consultó el 15 de octubre y fue adjudicada 2 de diciembre del citado año. Aporta pocas novedades respecto a los currícula anteriores. Ahora hace constar que tiene probados 40 (41, corrección manuscrita) años de estudios mayores en las facultades de Artes y Teología. También aumentan a 26 los actos mayores, permaneciendo invariables los cinco menores; 19 en la Facultad de Teología y manteniéndose los tres en la de Artes; y de los de teología fueron 13 mayores y 13 menores. Si hasta 1786 había opositado 10 (11, corrección manuscrita) veces, ahora eran 14 (15, corrección manuscrita), correspondiendo el aumento a la cátedra de Vísperas de Teología (ahora 4 veces) y a la de Lugares Teológicos (otras 4) ${ }^{15}$. En resumen, el teólogo Alba no acababa de alcanzar una cátedra de prestigio en su facultad, moviéndose en una de regencia (temporal) o en una de entrada de propiedad (Lugares Teológicos, explicados según Melchor Cano).

Basándonos en estas fuentes y otras, sobre todo en los distintos libros de la Universidad de Salamanca (de matrículas y claustros, fundamentalmente), podemos estructurar y resumir la trayectoria vital del maestro Alba en las siguientes etapas, algunas de las cuales se solapan, teniendo en cuenta la doble y paralela vida de fraile y de docente de la Universidad de Salamanca:

1. $\left.{ }^{a}\right)$ Nacimiento e infancia de Alba en Madrid (1735-1749). 2. ${ }^{a}$ ) Noviciado en el convento de los agustinos calzados de San Felipe el Real (Madrid, 11 de julio de

13. AUSA, Libro Procesos de cátedras 1016 (1784-1786), ff. 510 y ss. El currículum del maestro fray Antonio José de Alba aparece en la relación impresa de méritos, pp. 4-5.

14. AUSA, Libro Procesos de cátedras 1017 (1786-1791), ff. 116 y ss. Currículum de Antonio de Alba en la página 5 de la relación impresa de méritos.

15. AUSA, Libro Procesos de cátedras 1017 (1786-1791), ff. 413 y ss. Oposición a la cátedra de Prima de Teología que ganó fray Antonio Muñoz en 1791. Currículum de Antonio de Alba en las páginas 2-3 de la relación impresa de méritos. 
1749-18 de enero de 1751). 3. ${ }^{a}$ ) Estudios de artes o filosofía (1751-52 al 1753-54) en el colegio de Doña María de Aragón (Madrid). 4. ${ }^{a}$ ) Estudios de teología (cursos $1755-56$ al 1758-59) en el convento de Salamanca. $5 .^{a}$ ) Antonio Alba, profesor (lector) de artes y teología en el convento de Valladolid (cursos 1759-60 al 1762-63). 6. ${ }^{a}$ ) Retorno al convento de Salamanca (1763-1813). 6.1. ${ }^{\mathrm{a}}$ ) Grados de bachiller, licenciatura y doctorado en teología por la Universidad de Salamanca (1763-1764). 6.2. ${ }^{2}$ ) Alba, profesor de teología en el colegio de San Guillermo de San Agustín Calzado de Salamanca (1764-1772) y opositor frustrado hasta alcanzar la sustitución de la cátedra de Prima de Humanidades de la Universidad (1772). 6.3.. Presencia del maestro Alba en el origen de las reformas de las humanidades en la Universidad (1764-1770). 6.4.a $)$ Alba, opositor a las cátedras de filosofía natural y Prima de Humanidades (cursos 1770-1772). 6.5. ${ }^{a}$ ) Alba, catedrático sustituto de prima de humanidades (1772-1778). 6.5.1.a ) Alba, juez en los exámenes de preceptores de gramática (noviembre de 1775-noviembre de 1778). 6.6.a) El maestro Alba y el priorato de Diego Tadeo González en el convento de San Agustín de Salamanca (1775-1779). 6.7. a) Alba, catedrático de Teología en la Universidad de Salamanca (1778-1813). 6.8. a) El maestro Alba, referencia del convento agustino en la década 1780-1790. 6.9. ${ }^{\text {) }}$ ) Alba, asistente del general agustino en Roma (agosto de 1790-septiembre de 1791). 6.10. ${ }^{\text {a) }}$ Alba, columna vertebral del convento (17971813), después de la muerte de los maestros José Díaz (1796) y Madariaga (1797). 6.11. ${ }^{a}$ ) El vicerrector Alba en los preámbulos de la Guerra de la Independencia (1806-1808): la reforma educativa del ministro Caballero (1807) y el rectorado de Crespo Rascón. 6.12. ${ }^{\mathrm{a}}$ ) El vicerrector Alba, rector en funciones durante la Guerra de la Independencia (noviembre de 1809-enero de 1813). 6.13. ${ }^{a}$ ) El vicerrector Alba en la Universidad de Salamanca de 1809 y 1810. 6.14. ${ }^{a}$ ) El cafrancesado? vicerrector Alba y Paul Thiébault, gobernador napoleónico de Salamanca (1811-1812). 6.15. $\left.{ }^{a}\right)$ Los vaivenes político-militares de 1812 y la muerte del vicerrector Alba (22 de enero de 1813).

Comentando brevemente los rasgos más notables de su personalidad, como profesor de teología en el convento y en la Universidad salmantinos, subrayemos que en los cuatro cursos que van de 1776 a 1780, Alba se centra en la cátedra de Teología, olvidándose de las de Artes y de la de Humanidades, pues participa en tres nuevas oposiciones (nueve en total), dos a las de curso teológico (una en 1778) y otra a la de Lugares Teológicos ${ }^{16}$. En el currículum de 1787 había concurrido a once oposiciones, dos más que en 1780 (doce en total), una nueva a la de Vísperas de Teología y tres más (con la vacante presente) a Lugares Teológicos ${ }^{17}$.

16. AHN, Consejos, legajo 6011, expediente 108. Oposición a la cátedra de Vísperas de Teología de la Universidad de Salamanca en 1780.

17. AHN, Consejos, legajo 6024, expediente 97. Oposición a la cátedra de Lugares Teológicos vacante en la Universidad de Salamanca en 1787, pp. 5-6 de la Relación impresa de méritos. 
Aunque las relaciones de Alba y Meléndez se establecieron y fueron más profundas cuando el agustino fue catedrático sustituto de Prima de Humanidades (1772-1778), sin embargo, la amistad de Alba con Meléndez, menos conocida y publicitada que la de éste con Jovellanos, fue igual de sincera y más duradera, hasta 1808. Parece que en los diez años de destierro (1798-1808) se interrumpieron las relaciones entre Meléndez y Jovellanos, puesto que en los diarios del asturiano escritos en Mallorca no se encuentra ninguna mención de Meléndez. Tampoco nos consta que fuesen restablecidas cuando fueron rehabilitados en la primavera de 1808, pues Jovellanos permaneció descansando hasta el 17 de septiembre en Jadraque, mientras Meléndez lo creía retirado en Gijón (declaración en el proceso de Oviedo en el verano de 1808) ${ }^{18}$.

El maestro Alba proporcionaba libros a Meléndez, lector empedernido, como La Celestina ${ }^{19}$. En la égloga Batilo, premiada por la Academia en marzo de 1780, el poeta extremeño incluye, entre los personajes cubiertos por seudónimos poéticos de esta Arcadia salmantina, al padre Antonio José Alba bajo el nombre de Albano, con quien había seguido unos cursos de retórica y de poesía cinco años antes ${ }^{20}$.

La amistad de Antonio Alba con Meléndez Valdés fue duradera, como demuestra el hecho de que, estando el poeta desterrado en Medina del Campo, fuese visitado, al menos una vez, por el maestro agustino, rompiendo la monotonía de una vida que en dicho destierro sólo podía ser el estudio ${ }^{21}$. Por su parte, Meléndez se desplazó a Madrigal, donde los agustinos calzados tenían un convento, para ver al maestro Alba y asistir a la ceremonia del capítulo provincial de los agustinos $^{22}$. Residiendo los dos en Salamanca muchos años, se explica la escasez de correspondencia entre ambos, por eso cobran especial relevancia las dos únicas cartas conservadas ${ }^{23}$, que reproducimos en el apéndice. Están datadas en Zamora y Salamanca en octubre de 1801, momento crítico en el que Meléndez buscaba afanosamente testigos que avalasen su buen comportamiento, de ciudadano ejemplar, en el primer destierro en Medina del Campo (1798-1800), para desmontar las acusaciones de sus enemigos, que habían conseguido endurecer el destierro, ahora, en Zamora. El maestro Alba, aunque con cierto humor, satisfizo plenamente los deseos de su amigo desterrado.

18. Astorgano. Don Juan Meléndez Valdés. El Ilustrado. Badajoz: Diputación Provincial, 2007, pp. 319, 524-530.

19. Demerson, Georges. Don Juan Meléndez Valdés y su tiempo 1754-1817. Madrid: Taurus, 1971, t. I, p. 106.

20. Demerson. Don Juan..., cit., t. I, pp. 61-63, 83.

21. Demerson. Don Juan..., cit., t. II, p. 384.

22. Demerson. Don Juan..., cit., t. I, pp. 358, 373. EsPerabé De ArTeaga, Enrique. Historia pragmática..., cit., vol. II, p. 722 .

23 RAE, RM, Caja 61/2, pieza 11, ff. 61r.-63v. Original autógrafo en RAE, RM, Caja 61/2, pieza 19, ff. 103r.-106r. 


\section{Alba, CATEDRÁtico de Teología (1778-1813)}

Son más de 35 años, de los que, apenas, se sabe que en 1778 Alba toma posesión de una regencia de Teología, que ocupa hasta 1807 en que, por las reformas introducidas en el Plan de estudios del ministro José Antonio Caballero, pasó a la de Lugares Teológicos (1807-1812) y, después, a la de Religión o Teología Moral $(1812-13)^{24}$. Aunque Santiago Vela le pierde la pista vital al maestro Alba en 1791, sin embargo, vivió 22 años más (1791-1813), de los cuales los cuatro últimos fueron de una intensa actividad universitaria, como vicerrector, en funciones de rector, capeando bastante eficientemente el vendaval destructor de la Guerra de la Independencia.

Esta decidida vocación a los estudios y el haber conseguido una de las cátedras de regencia de Teología en 1778 debieron influir en su designación para un cargo importante interno de la Orden, que encontramos en el currículum de 1780: "Es prefecto de los estudios de su provincia por nombramiento especial de su general ${ }^{25}$, que se repite textualmente en $1787^{26}$, y que mantendrá hasta que en 1790 sea nombrado asistente del general de los agustinos calzados, y tenga que trasladarse a Roma.

Esa treintena larga de años (1778-1813) de profesor de teología permanece bastante oscura, a pesar de contar con una magnífica guía de investigación, como son los libros de la Universidad de Salamanca, en especial los de claustros. El carácter discreto y prudente lo llevó a impulsar los proyectos reformistas en la sombra, como el Colegio de Filosofía. Sólo cuando le fue imprescindible asumir responsabilidades en primera persona lo hace durante la ocupación francesa.

Repasemos los datos de su vida que se pueden espigar en diversas fuentes. En 1779 preside, por comisión del general de la Orden, el Capítulo Provincial de Castilla celebrado en el mes de abril ${ }^{27}$. En 1780 publica, aunque debió redactarse algún tiempo antes, la oración fúnebre El Filósofo, en honor del franciscano observante maestro Manuel Fernández, moderante de la Academia de Teología, fallecido en diciembre de 1772 o enero de 1773. En los años 1780-82 Alba protegió decididamente a dos grabadores tipográficos con la intención de establecer una imprenta universitaria para abaratar la difusión de manuales y novedades editoriales; proyecto que fracasó ante la oposición del profesorado más tradicionalista (los catedráticos de regencia, en especial los teólogos), que prefería destinar el dinero a mejorar sus salarios, lo que obligó al agustino a pedir informes a los mejores grabadores, fundidores e impresores de Madrid (incluido Joaquín Ibarra)

24. MuÑoz Delgado, Vicente. "La Universidad de Salamanca (1778)...», cit., pp. 153-54.

25. AHN, Consejos, legajo 6011, expediente 108.

26. AHN, Consejos, legajo 6024, expediente 97.

27. Santiago Vela. Ensayo de una Biblioteca Ibero-Americana..., cit., vol. I, p. 104. 
en octubre de $1782^{28}$. Meléndez apoyará decidida, pero infructuosamente, este proyecto entre 1784 y 1786 en los claustros plenos ${ }^{29}$.

En mayo de 1788 Alba forma parte de la comisión para organizar un colegio de filósofos y matemáticos, impulsado por el catedrático de Matemáticas Juan Justo García, a fin de elevar el nivel de las Artes, siendo uno de los que proponen la sustitución de la Física de Aristóteles por la moderna ${ }^{30}$.

Alba intervino en la confección del Plan de 1807 y estuvo encargado de informar sobre el mismo, proponiendo como texto recomendable de lógica el Arte de pensar o Lógica de Port-Royal de los jansenistas Pierre Nicole-Antoine Arnauld ${ }^{31}$, muy popular en Salamanca durante el XVIII, obra fundamental en la historia de esta disciplina, distinguida por la acusada influencia del cartesianismo, siendo utilizada como manual elemental hasta el siglo xx. Alba continuó hasta el fin de su carrera docente afincado ideológicamente en el bando reformista y filojansenista de la Universidad, como casi treinta años antes (1778) había mirado con simpatía la Lógica contenida en los Elementa del mexicano Benito Díaz de Gamarra ${ }^{32}$.

En el curso de 1812 figura como catedrático de Religión (Teología Moral) y permaneció en esta cátedra hasta su muerte, ocurrida el 22 de enero de 1813. Tuvo un papel muy importante, pues, como vicerrector más antiguo, el «doctor» (que no maestro) Antonio Alba dirigió la Universidad de Salamanca, y tuvo el honor de convocar el miércoles 15 de julio de 1812 y presidir el claustro pleno y de catedráticos del 16, en el que se leyó y juró la Constitución de Cádiz (la «Constitución política de nuestra monarquía») ${ }^{33}$. Después de leer la carta del marqués de Monsalud del 5 de julio que presentaba un ejemplar de la Constitución, "se leyó en alta voz toda la expresada Constitución de verbo ad verbum", acordándose "que se jure inmediatamente en este mismo claustro y que se designe desde luego la cátedra de Recopilación para su enseñanza», según había propuesto el doctor José Ayuso Navarro ${ }^{34}$.

La vinculación ininterrumpida de Alba con la Universidad de Salamanca está documentada en los libros de matrículas y de claustros. Siendo rector Narciso Bátiz, el 2 de diciembre de 1782, el prior Ramón Nicolás Zurdo matrícula a 49

28. AUSA, Libro de Claustros 242, ff. 825r.-877v. Claustro pleno de 29 de octubre de 1782 presidido por el rector ilustrado Carlos López Altamirano.

29. AUSA, Libro de Claustros 243, f. 175 (claustro pleno de 10 de mayo de 1784); DEMERSON. Don Juan..., cit., t. I, pp. 211-212; Astorgano. Don Juan Meléndez Valdés. El ilustrado, cit., p. 254.

30. MuÑoz Delgado, Vicente. "La Universidad de Salamanca (1778)...», cit., p. 154.

31. NiCOlE, Pierre y ARNAUld, Antoine. La logique ou L'art de penser: contiene las reglas comunes, varias observaciones nuevas, dirigidas a formar el pensamiento. Paris: G. Desprez, 1683.

32. MuÑoz Delgado, Vicente. "La Universidad de Salamanca (1778)...", cit., pp. 153-154.

33. AUSA, Libro de Claustros 260 (1810-1813), ff. 359-361.

34. AUSA, Libro de Claustros 260, ff. 400r.-401r. José Ayuso Navarro, convencido reformista desde joven, doctor en Leyes y amigo de Meléndez, había sido catedrático de Griego desde 1786 (apoyado por Batilo, juez en dicha oposición), y llegará a ser magistrado de las Audiencias de Valencia y Granada. 
frailes, además del catedrático regente de Teología Antonio Alba, y del reverendo padre maestro José Díaz, opositor en teología, lista fechada el 16 de noviembre de $1782^{35}$. No aparece Madariaga, porque estaba en Roma, como asistente del general Vázquez ${ }^{36}$. Llegado el curso 1783-84, siendo el segundo año del rectorado de Narciso Bátiz, el 26 de noviembre de 1783 se matriculan 50 agustinos calzados ${ }^{37}$.

Siendo rector José de Azpeitia de Izaguirre, el 23 de noviembre de 1784 son inscritos 50 frailes agustinos, con el prior Francisco Sarriá a la cabeza ${ }^{38}$. En la lista de maestros y doctores el maestro agustino José Díaz aparece como opositor en teología, pero no figuran los maestros Madariaga (asistente en Roma) ni Alba ${ }^{39}$. Para el curso 1785-86, segundo año del rectorado de José Azpeitia, el prior Francisco Sarriá matrícula 51 frailes el 6 de diciembre ${ }^{40}$. No encontramos al maestro Pedro de Madariaga, el cual continuaba como asistente de su general Francisco Javier Vázquez. Están en la lista de doctores, fechada el 20 de noviembre de 1785, el maestro Antonio Alba, catedrático de regencia de Teología, y José Díaz, opositor en teología ${ }^{41}$.

Siendo vicerrector Juan Eugenio Ximénez, el 16 de diciembre de 1786, el prior Francisco Sarriá matrícula los 56 frailes de la comunidad agustina calzada ${ }^{42}$, además del catedrático regente de Teología Antonio José Alba; de fray José Díaz (opositor en teología), y del catedrático de Filosofía Moral, Pedro de Madariaga, el cual aparece por primera vez después de su estancia en Roma en la lista de catedráticos datada el 4 de diciembre ${ }^{43}$.

El curso 1787-88 era el primer año del rectorado del reformista extremeño Diego Muñoz Torrero, cuyas iniciativas apoyaron los agustinos en los distintos claustros plenos y en las juntas especializadas en las que estuvieron presentes. El 4 de diciembre de 1787 se matrícula el convento de San Agustín, dirigido por el prior Francisco Sarriá ${ }^{44}$. En total 52 frailes, más los tres claustrales, que figuran en la lista de doctores y maestros, Pedro de Madariaga y Antonio José de Alba regentando las conocidas cátedras de Filosofía Moral y de Teología respectivamente, y José Díaz opositando a teología ${ }^{45}$. Siendo el segundo año del rectorado de Diego Muñoz Torrero, el 2 de diciembre de 1788, se inscriben 52 frailes, sin aparecer claro quién era el prior, aunque la comunidad está encabezada por el padre Santos

35. AUSA, Libro de matrículas 490, f. $8 \mathrm{v}$.

36. AUSA, Libro de matrículas 490, f. 2.

37. AUSA, Libro de matrículas 491, f. 7v.

38. AUSA, Libro de matrículas 492, f. 10r.

39. AUSA, Libro de matrículas 492, f. 2.

40. AUSA, Libro de matrículas 493, f. 9v.

41. AUSA, Libro de matrículas 493, f. 2.

42. AUSA, Libro de matrículas 494, f. 10.

43. AUSA, Libro de matrículas 494, f. 3.

44. AUSA, Libro de matrículas 495, f. 8.

45. AUSA, Libro de matrículas 495, f. 2. 
Mediavilla ${ }^{46}$. Entre los doctores y maestros figuran Madariaga y Alba en sus respectivas cátedras, ya sabidas. El maestro José Díaz ha dejado de ser opositor para ocupar la moderantía o dirección de la academia de teología.

Para el curso 1789-90, siendo rector el licenciado Vicente Ruiz Alvillos y vicerrector Juan Manuel Martínez, el 8 de enero de 1790 se inscribe una comunidad agustiniana de 53 miembros, sin especificar los empleos de sus dirigentes ${ }^{47}$. Continúan los maestros Madariaga, José Díaz y Antonio Alba, pero sin indicar las cátedras que regentaban. Alba estuvo gran parte de este curso alejado de las aulas preparando su viaje a Roma como asistente del general de los agustinos, y cuya llegada a Bolonia el 3 de agosto de 1790 registra el padre Manuel Luengo el 23 del mismo mes ${ }^{48}$.

Siendo rector el licenciado Francisco Antonio Bajo y vicerrector Félix Sanz, el 7 de enero de 1791 se matrícula para el curso 1790-91 la comunidad de 53 agustinos calzados, dirigida por el subprior Ramón Estévez, aunque también figura un Juan Fernández que muy probablemente sea el poeta Juan Fernández de Rojas (el Liseno del Parnaso salmantino), quien aparecerá como prior en los dos cursos siguientes ${ }^{49}$. Entre los frailes encontramos por primera vez a fray José de la Canal (1768-1845), quien llegará a ser director de la Real Academia de la Historia (1844), además de dos frailes con el apellido Madariaga, que suponemos parientes del maestro del mismo apellido. Por lo tanto, teniendo en cuenta que el priorato solía durar tres años, Juan Fernández de Rojas dirigió el convento de San Agustín de Salamanca en los cursos 1791-92 al 1793-94. En este curso figura, por primera vez, jubilado de su cátedra de Filosofía Moral, el maestro Pedro de Madariaga ${ }^{50}$. En la lista de maestros y doctores de la Universidad aparece la irregularidad de estar inscrito el padre Antonio Alba cuando sabemos que estuvo en Roma hasta el verano de 1791. Respecto al maestro José Díaz sólo se señala que era opositor a teología.

Siendo vicerrector de la Universidad y encargado del rectorado el bachiller Ildefonso Ceballos, prior del convento Juan Fernández de Rojas y subprior Ramón Estévez, el 20 de noviembre de 1791 se matricula (el primero de los inscritos ese año) el convento de San Agustín con 54 frailes $^{51}$, figurando Pedro de Madariaga, catedrático de Filosofía Moral jubilado, y Antonio José de Alba en la consabida cátedra de regencia de Teología ${ }^{52}$. El maestro Díaz no aparece ni entre los maestros de la Universidad ni entre los frailes de la comunidad.

46. AUSA, Libro de matrículas 496, f. 8.

47. AUSA, Libro de matrículas 497, f. 11.

48. Luengo, Manuel. Diario de la expulsión de los jesuitas de los dominios del rey de España... Archivo Histórico de Loyola, Sección: Escritos de jesuitas del xviII, 49 vols. [Citado como Diario]. Cita en Diario, día 23.8.1790.

49. AUSA, Libro de matrículas 498, f. 13.

50. AUSA, Libro de matrículas 498, f. 4.

51. AUSA, Libro de matrículas 499. Matrículas del curso 1791-92, f. 9.

52. AUSA, Libro de matrículas 499, f. 4. 
Siendo el primer año del primer rectorado del doctor Juan Francisco Gorordogoicoa $^{53}$, el 1 de diciembre de 1792 el prior Juan Fernández de Rojas matrícula 55 frailes, entre los que figuraban el subprior Ramón Estévez y el predicador general Martín Arrugaeta ${ }^{54}$. En la lista de maestros y doctores del 23 de noviembre de 1792 (incompleta: sólo trece inscritos) aparece el catedrático jubilado de Filosofía Moral Pedro Madariaga, aunque no figuran José Díaz ni Antonio José de Alba (a pesar de que hacía más de un año que había regresado de Roma). Para el curso 1793-94, segundo año del rectorado de Gorordogoicoa, el 27 de noviembre de 1793 el prior Juan Fernández de Rojas inscribe 52 frailes $^{55}$. Entre los doctores y maestros aparecen el catedrático jubilado de Filosofía Moral Pedro de Madariaga y el que le sustituiría Miguel Martel (en este momento como catedrático de Matemáticas), y Antonio José de Alba en su cátedra de regencia de Teología ${ }^{56}$.

El curso 1794-95 fue el primer año del rectorado del doctor Luis Casaseca y Tomé. El 19 de noviembre, el prior Celedonio Urrutia y el subprior Ramón Estévez matriculan 44 frailes, entre los que ya no aparece Juan Fernández de Rojas, el cual cumplidos los tres años de su priorato había abandonado Salamanca y retornado a su convento de San Felipe el Real en Madrid ${ }^{57}$. En la lista de maestros y catedráticos el número dos en antigüedad era el jubilado Madariaga, figurando también Antonio de Alba ${ }^{58}$. Siendo el segundo año del rectorado del doctor Luis Casaseca Tomé, el 4 de febrero de 1796, es decir, bastante tardíamente, el prior Celedonio Urrutia y el nuevo subprior Gabriel Irarzábal matriculan sólo 12 frailes, sin que sepamos el motivo de la espectacular bajada respecto a los años anteriores ${ }^{59}$. En la lista de doctores y catedráticos sólo hay cuatro inscritos, incluido el jubilado Pedro Madariaga, pero no Antonio José de Alba ni José Díaz.

El 16 de diciembre de 1796, siendo el primer año del segundo rectorado del doctor Juan Francisco Gorordogoicoa, el prior Celedonio Urrutia y el subprior Irazábal inscriben a 47 frailes $^{60}$. En la lista de catedráticos, confeccionada el 30 de noviembre de 1796, aparecen los dos agustinos, Madariaga y Alba ${ }^{61}$, pero no José Antonio Díaz, fallecido el 2 de febrero de $1796^{62}$. El curso 1797-98 fue el segundo año del segundo rectorado de Juan Francisco Gorordogoicoa, que coincidió con el ministerio de Gracia y Justicia de Jovellanos, con la fiscalía de Meléndez Valdés

53. Excepcionalmente, el Dr. D. Juan Francisco Gorordogoicoa tuvo tres rectorados: 1792-94; 1796-98 y 1800-1801.

54. AUSA, Libro de matrículas 500, ff. 11v.-12r.

55. AUSA, Libro de matrículas 501, ff. 8v.-9r.

56. AUSA, Libro de matrículas 501, ff. 3-5.

57. AUSA, Libro de matrículas 502, ff. 14v.-15r.

58. AUSA, Libro de matrículas 502, f. 3.

59. Probablemente por negligencia del funcionario, pues tampoco están completas otras listas, como la de maestros y doctores. AUSA, Libro de matrículas 503, f. 17

60. AUSA, Libro de matrículas 504, f. 11.

61 AUSA, Libro de matrículas 504, ff. 1-3.

62. Santiago Vela. Ensayo de una Biblioteca Ibero-Americana..., cit., vol. II, pp. 228-230. 
en la Sala de Alcaldes de Casa y Corte ${ }^{63}$ y con el nombramiento de Antonio Tavira Almazán como obispo de Salamanca el 14 de agosto de $1798^{64}$. En la página dedicada al convento de San Agustín no hay ningún nombre y sólo la siguiente nota: "pagó 30 reales»" ${ }^{65}$. En la lista de catedráticos lógicamente no aparecen los fallecidos Pedro de Madariaga ${ }^{66}$ y José Díaz, pero sí el maestro Alba, quien por edad y prestigio queda con la máxima autoridad moral del convento ${ }^{67}$.

Hay un periodo de tres cursos (1798-99 al 1800-1801) con escasez de datos sobre las matrículas en la Universidad de Salamanca. El libro de matrículas del curso 1798-99, siendo rector el licenciado D. Francisco Javier Caro y vicerrector el bachiller Juan González, es muy defectuoso, pues no hemos encontrado la comunidad de agustinos y la lista de doctores y catedráticos aparece en blanco ${ }^{68}$. El libro 507, correspondiente a las matrículas del curso 1799-1800, se ha perdido. En el libro de matrículas del curso 1800-1801, siendo el primer año del vicerrectorado del bachiller Juan González Maldonado, si bien casi todos los claustros están convocados y presididos por el vicerrector José Cartagena, no aparece ni el colegio de San Agustín ni la lista de doctores y catedráticos ${ }^{69}$. Por el libro de claustros nos consta la actividad del maestro Alba. Por ejemplo, es uno de los dos claustrales que firma el claustro pleno celebrado el 16 de junio de $1801^{70}$.

Para el curso 1801-1802, siendo el primer año del rector doctor Miguel Ortiz Rufrancos y segundo curso del vicerrectorado de Juan González Maldonado, el 16 de marzo de 1802 el prior Alonso Álvarez y el subprior Gabriel Irazábal inscriben 51 frailes, entre los que figuran fray Martín Madariaga y Domingo Madariaga, maestro de novicios, a los que le suponemos algún parentesco con el fallecido Pedro Madariaga ${ }^{71}$. En la lista de doctores y catedráticos, fechada el 11 de febrero de 1802, el reverendísimo Antonio José Alba aparece con el número 7 en antigüedad ${ }^{72}$. Siendo el segundo año del rector Miguel Ortiz de Rufrancos, el 4 de diciembre de 1802 la comunidad de agustinos calzados, dirigida por el prior

63. Astorgano, Antonio. «El paso de Jovellanos y Meléndez Valdés por el Ministerio de Gracia y Justicia (1798)». Revista de Estudios Extremeños, 1999, 55-3, pp. 995-1052.

64. Guitarte IzQuierdo, Vidal. Episcopologio Español (1700-1867). Castellón de la Plana: Ayuntamiento, 1992, p. 109.

65. AUSA, Libro de matrículas 505, f. 19.

66. Madariaga falleció en Salamanca el 14 de mayo de 1797. SANTIAgo Vela. Ensayo de una Biblioteca Ibero-Americana..., cit., vol. V, pp. 153-155.

67. AUSA, Libro de matriculas 505, f. 1.

68. AUSA, Libro de matrículas 506. Matrículas del curso 1798-99.

69. AUSA, Libro de matrículas 508. Matrículas del curso 1800-1801.

70. AUSA, Libro de matrículas 254, ff. 183-188.

71. AUSA, Libro de matrículas 509, f. 14.

72. AUSA, Libro de matrículas 509, f. 1. 
Alonso Álvarez, matricula 48 frailes $^{73}$. El maestro Alba aparece con el número seis en antigüedad en la lista de doctores ${ }^{74}$.

El 10 de diciembre de 1803 el prior fray José Sologurón inscribe 51 frailes, siendo rector Francisco Laforcada, catedrático jubilado de Leyes ${ }^{75}$. Siendo el segundo año del rectorado de Francisco Laforcada, el 24 de noviembre de 1804 se matricula la comunidad de agustinos calzados, siendo la primera en hacerlo, con un total de 42 frailes $^{76}$. Alba ocupa el sexto lugar en el escalafón de los doctores y maestros (94 individuos) ${ }^{77}$.

Siendo rector el licenciado Antonio Cabanillas, la comunidad de agustinos calzados, dirigida por el padre visitador fray Agustín Villoria, el 27 de noviembre de 1805 inscribe 41 frailes para el curso 1805-1806 ${ }^{78}$.

Siendo rector el doctor Francisco Crespo Rascón, en su primer año, el 3 de diciembre de 1806 se matrícula la comunidad agustiniana, encabezada por el prior Francisco Domínguez. Son 44 frailes, además del vicerrector maestro Antonio José de Alba, el número 6 de los maestros y doctores ${ }^{79}$. En el curso siguiente, segundo año del rectorado de Crespo Rascón y del vicerrector Alba, el 17 de diciembre de 1807 se inscribe la comunidad agustiniana, compuesta por 37 miembros, con el padre Francisco Domínguez a la cabeza, abonando un total de 111 reales $^{80}$.

Siendo rector de la Universidad Andrés Ramos Martín, el 28 de noviembre de 1808, la comunidad agustina es la primera que se inscribe para el curso 18081809, si bien, debido a las difíciles circunstancias bélicas, sólo se matrícula fray Marceliano Torío, aunque sin pagar la matrícula, según anotación del funcionario, "no pagada" ${ }^{81}$. El conflicto bélico había dispersado a la comunidad educativa y en noviembre de 1809 el vicerrector Alba se responsabiliza de la dirección de la Universidad durante el resto de la guerra hasta su muerte en enero de 1813.

En estos años anteriores a la Guerra de Independencia fray Antonio José Alba siempre aparece entre los maestros y doctores, ocupando los puestos cinco o seis en antigüedad. Como vicerrector y miembro del equipo del rector Crespo Rascón, Alba impulsó el modernizador plan de estudios del ministro Caballero (1807).

73. AUSA, Libro de matrículas 510, ff. 10r.-10v.

74. AUSA, Libro de matrículas 510, f. 2.

75. AUSA, Libro de matrículas 511, ff. 14v.-15r. Curiosamente aparece la lista de licenciados, pero no la de doctores y maestros.

76. AUSA, Libro de matrículas 512, f. 8r.

77. AUSA, Libro de matrículas 512, f. 1r.

78. AUSA, Libro de matrículas 513, ff. 11v.-12r.

79. AUSA, Libro de matrículas 514, f. 10r.

80. AUSA, Libro de matrículas 515, ff. 10v.-11r.

81. AUSA, Libro de matrículas 516, f. 7r. 


\section{El JANSENISMO-REFORMISMO DEL MAESTRO AlBA}

Aludiremos brevemente a dos rasgos significativos, aunque polémicos, de la personalidad del maestro Alba. En otro lugar hemos estudiado el jansenismo dentro del convento de los agustinos calzados de Salamanca en 1765 y el enfrentamiento del mismo con los jesuitas, a propósito de la doctrina del cardenal Enrique Noris y Juan Lorenzo Berti, todo presenciado por el nuevo doctor en Teología Alba (1764). Ahora nos fijaremos en la imagen, igualmente filojansenista, que casi treinta años después daban el convento y su maestro Alba, recién nombrado asistente del general agustino Stephano Bellisini (1786-1797) en Roma (1790-1791).

No podemos extendernos en el amplio, equívoco y confuso concepto de «jansenismo». Se suelen distinguir en este movimiento teológico, filosófico y político tres ramas: jansenismo teológico, jansenismo moral-espiritual (influyente en el rigorismo moral en los siglos XVIII y XIX) y jansenismo político-antijesuítico-galicanista (considerado como el movimiento mayoritario dentro del jansenismo). Cuando hablamos del jansenismo de los agustinos nos referimos oclusivamente a este último, pues en el plano teológico eran tan ortodoxos o más que sus acusadores los jesuitas, como demuestra la cerrada defensa que el papa Benedicto XIV hizo del cardenal Noris y el enfado que le causó el que los jesuitas lo incluyesen en el Índice último de libros probibidos de $1747^{82}$, llegando a declarar nula, por medio de un Breve de 19 de febrero de 1749, la censura e inclusión en dicho Índice de las obras de Noris, hecha por los jesuitas hispánicos José Carrasco y José Casani.

\subsection{El jansenismo-reformismo de Alba en 1790}

El curso 1789-90, el primero sin la presencia del catedrático Meléndez Valdés, destinado como alcalde del crimen en Zaragoza, fue de bastantes cambios en los catedráticos agustinos, Madariaga y Alba. En los claustros plenos y en las juntas del curso 1789-90 hay dos asuntos interesantes para nuestro estudio y que salen con cierta frecuencia: la solicitud, informes y aceptación de la jubilación de Pedro de Madariaga en su cátedra de Filosofía Moral, y la oposición a la cátedra de Prima de Humanidades que había dejado vacante Meléndez al trasladarse a Zaragoza en septiembre de 1789 .

Antonio de Alba está presente en el claustro pleno del 27 de noviembre de 1789. También asiste a la junta de la academia de teología del 19 de enero de 1790, convocada para designar visitador de la academia de teología. A partir de febrero

82 Egido, Teófanes. "La expulsión de los jesuitas de España». En García-Villoslada, Ricardo (dir.). Historia de la Iglesia en España, vol. IV, La Iglesia en la España de los siglos XVII y XVIII. Madrid: Biblioteca de Autores Cristianos, 1979, pp. 776-780; EGIDO, Teófanes. Los jesuitas en España y en el mundo. Madrid: Fundación Carolina, Centro de Estudios Hispánicos e Iberoamericanos, Marcial Pons, 2004, p. 240. 
de 1790, Alba desaparece de los claustros y juntas universitarios, tal vez porque estuviese preparando su viaje a Roma.

En el claustro de consiliarios del 20 de enero de 1790 se trató de nombrar sustituto del jubilado padre Madariaga ${ }^{83}$. En el claustro de consiliarios del 3 de febrero de 1790 se nombraron sustitutos de las cátedras de regencia que no los tenían y se declaró vacante la cátedra de Humanidad que había dejado Juan Meléndez Valdés. Como sustituto de la cátedra de regencia de Teología del maestro Alba se nombró a don Eugenio Villarande ${ }^{84}$.

El día 15 de marzo de 1790 se trata de la manera de presentar los edictos que anunciaban la oposición a la cátedra de Filosofía Moral por jubilación de Pedro Madariaga ${ }^{85}$. En el claustro pleno del 21 de abril de 1790 y en claustros sucesivos se trata repetidas veces sobre la oposición a la cátedra de Humanidad dejada vacante por Juan Meléndez Valdés ${ }^{86}$.

En el claustro de vicerrector y consiliarios del 1 de junio de 1790 se nombra sustituto de la cátedra de regencia de Teología que hasta la fecha estaba desempeñando Antonio Alba ${ }^{87}$, señal evidente de que estaba a punto de emprender el viaje a Italia. En la cédula de convocatoria se citaba, "para oír una proposición mía [del vicerrector, bachiller don Félix Sanz] acerca de una sustitución de la cátedra de regencia que ha leído el reverendo Alba [...], y en su vista pasó el señor vicerrector a proponer sustituto de la cátedra del señor Alba, y propuso a Manuel Otero Saavedra; [...] resultando tener el bachiller Manuel Otero Saavedra cuatro votos, y Francisco Javier Vales un voto» ${ }^{88}$. A partir de ahora en los claustros están frecuentemente presentes Pedro de Madariaga y José Díaz, pero no Antonio de Alba.

Son muy pocas la alusiones que se hacen por los historiadores al cargo más importante que tuvo Alba dentro de su orden religiosa, la de asistente en Roma del general agustino Stephano Bellisini (1786-1797), elegido el 3 de junio de 1786 para sustituir al peruano Francisco Javier Vázquez, regalista y antijesuita declarado, gracias a los votos de los franceses e italianos, derrotando a otros candidatos como Pedro Madariaga o Agustín Antonio Giorgi, más antijesuitas y jansenistas, en opinión de Luengo ${ }^{89}$.

Más imprecisa es la duración del mismo. Sólo hemos visto la noticia de que pidió permiso para ausentarse de su cátedra por seis años. Con certeza se puede afirmar que hizo el viaje, pues, como ya sabemos, el 3 de agosto de 1790 llegó a Bolonia, y que este empleo, que solía durar como mínimo un trienio, Alba sólo lo desempeñó durante un año justo (agosto 1790-septiembre de 1791,

83. AUSA, Libro de claustros 248, f. 88r.

84. AUSA, Libro de claustros 248, ff. 113r.-114v.

85. AUSA, Libro de claustros 248, ff. 196r.-198r.

86. AUSA, Libro de claustros 248, f. $270 \mathrm{r}$.

87. AUSA, Libro de claustros 248, f. 297r.

88. AUSA, Libro de claustros 248, f. 298r.

89. Luengo, Manuel. Diario, día 25.6.1786. 
aproximadamente), porque los libros de claustros salmantinos atestiguan su presencia a mediados de octubre de 1791.

Aportamos el testimonio de uno de sus contrincantes ideológicos, el jesuita desterrado P. Manuel Luengo ${ }^{90}$, redactado el 23 de agosto de 1790, con motivo del viaje que Antonio Alba hizo a Roma, pasando por Bolonia, donde descansó unos veinte días:

El día 3 de este mes de agosto [1790] llegó a esta Ciudad de Bolonia, viniendo últimamente de la Corte de Madrid, el P. Maestro Alba, Agustino Calzado, Doctor en la Universidad de Salamanca. Algún otro año antes del destierro de los jesuitas había tomado el grado en la dicha Universidad [1764], y así es conocido de todos los jesuitas que en los últimos años vivieron en aquel Colegio Real de Salamanca, y mucho más de los que entonces eran Maestros. [...] Este P. Maestro Alba llegó a esta Ciudad muy acalorado de su viaje y algo indispuesto, y por esta causa, o por otra oculta, se ha detenido todo este tiempo en este Convento de Santiago de su Orden, y ha pasado algunos días en una Casa de Campo de estos Religiosos, y estando en ella convidó un día a comer a dos de los jesuitas españoles con quienes ha tratado con mayor franqueza e intimidad; y al presente se dispone a continuar su viaje a Roma, donde será Asistente de la Asistencia de España ${ }^{91}$.

Antes de la expulsión de los jesuitas en abril de 1767, el maestro Alba ya era conocido entre los jesuitas salmantinos, por su posición contraria a la Compañía de Jesús (polémica sobre el jansenismo de Noris en 1765), de manera que tuvo un papel importante en la expulsión, ya que se encargó de registrar y catalogar la documentación incautada a los ignacianos expulsos, siendo gratificado con cien doblones:

Yo [Luengo] le conocí lo bastante para poder asegurar no solamente que se conformó muy bien con el espíritu, máximas y conducta de su Orden en aquel tiempo, y generalmente de todos sus Hermanos, que consistían en mostrarse en todo contrarios y enemigos de los jesuitas, sino también que sobresalía y se aventajaba a muchos en esta honrosa carrera. Y en la expulsión de los jesuitas, sobre los motivos comunes a los demás Regulares, tuvo uno personal para aplaudirla y celebrarla. Este Maestro Alba, con algún otro, fue señalado para registrar la Librería y Archivo del dicho Colegio [de la Compañía], y para reconocer los manuscritos y los papeles que se encontrasen. No es fácil saber si en esta operación, que era muy a propósito para el caso, hizo alguna villanía con el fin de adular a los poderosos enemigos de los

90. Luengo había cursado la Teología en el Real Colegio de Salamanca (1758-62), donde fue ordenado sacerdote, una vez finalizado su tercer año, el 21 de septiembre de 1761, por el obispo auxiliar salmantino, monseñor San Andrés. Completada su formación jesuítica con la Tercera Probación, inició su vida activa enseñando Filosofía en Salamanca y Medina del Campo y, tras unos meses como ministro en el Colegio de Arévalo, reanudó la docencia de la Filosofía en el Colegio de Santiago de Compostela, en donde le sobrevino la orden de expulsión de la Compañía por Carlos III, el 3 de abril de 1767 .

91. Luengo. Diario, día 23.8.1790. 
jesuitas y de infamarles a ellos. Pero se sabe con certeza que, además del honor de una comisión de tanta confianza, tuvo el gusto de que le regalasen por su trabajo 100 doblones de los bienes del Colegio ${ }^{92}$.

En el destierro italiano los jesuitas continuaban guardando un recuerdo negativo del «jansenista» maestro Antonio Alba, enemistad que el agustino, debido a su carácter abierto y "remilgado", lejos de ocultar, exhibía irónicamente:

Éstos [los cien doblones de recompensa] le supieron tan bien que [Alba] casi deseaba que volvieran los jesuitas para ganar otros tantos. En carta de España, digna de crédito, que yo vi hace ya varios años, se contaba sobre este asunto este gracioso pasaje. En una conversación de varias personas se habló una vez, como acá y allá ha sucedido cien veces, de regreso y aun de restablecimiento de los jesuitas, y en esta ocasión dijo este agustino Alba que él se alegraría mucho de que volviesen y fuesen restablecidos otra vez los jesuitas, porque ellos, añadió muy remilgadillamente, como habla de todos los asuntos, no tardarian mucho tiempo en hacer méritos para ser echados otra vez de España, y yo tendría el gusto de ganarme otros 100 doblones $^{93}$.

Solía ocurrir que los enemigos de los jesuitas, con el transcurso de los años, aflojaban su furor antignaciano, e incluso mostraban arrepentimiento de haberlos perseguido. Éste era el caso del maestro Alba:

No obstante todo esto, [Alba] ha mostrado aquí gusto y aun empeño algo particular en ver y tratar a los Maestros [jesuitas] que conoció en España, y a algún otro, por respeto a sus familias o a algunos parientes suyos; y en todas estas visitas y conversaciones, a lo que me cuentan los mismos que han tratado con él, se ha mostrado compadecido con nuestros trabajos y desprecios, y ha hablado con bastante franqueza y familiaridad, como si quisiera empezar a ser nuestro amigo y apasionado. Así se han portado, por lo común con nosotros en esta Ciudad [Bolonia], todos los españoles al venir de España, aunque fuesen poco afectos a los jesuitas, y aun enemigos declarados suyos, como este agustino Alba, y su hermano y condoctor el Maestro Madariaga ${ }^{94}$.

En muchos casos Luengo observa que los viajeros, a la vuelta de Roma, regresaban más antijesuíticos, cambio que él atribuía al influjo de los regalistas españoles residentes en la corte del Vaticano, sobre todo al embajador José Nicolás de Azara:

Pero si éste [Alba] se detiene en Roma algunos años y vuelve a pasar por aquí hacia España, ya volverá esquivo y desabrido para con los jesuitas, y con la cabeza llena

92. LuENGO. Ibídem.

93. LUENGO. Ibídem

94. LuEngo. Ibídem. Resumen biográfico de Pedro de Madariaga en Simón ReY, Daniel. Las facultades de Artes y Teología de la Universidad de Salamanca en el siglo XVIII. Salamanca: Universidad, 1981, pp. 243-245. 
de delirios y necedades que le habrán metido en ella los romanos, como les ha sucedido generalmente a todos los demás ${ }^{95}$.

El pensamiento de Alba en 1790 continuaba siendo aperturista, reformista y filojansenista ("la teología de Lyon»), según Luengo:

Dos cosas solamente de las muchas de que ha hablado este maestro Alba en sus conversaciones con estos jesuitas, mis amigos, merecen ser notadas en este Diario. La primera es que en la empresa de introducir en la Universidad de Salamanca la Suma de Teología de Lyon ha habido los pasos que insinuamos en este escrito, y que el Sr. Lectoral Ramos [el filojesuita doctor Custodio Ramos] es el que con más fuerza y calor se opuso a este proyecto y que a él principalmente se le debe que no se haya ejecutado, y que está o abandonado o suspendido a lo menos. Pero [Alba] no se ha explicado con claridad y franqueza, en cuanto he podido averiguar, sobre su voto y parecer en este caso y sobre el de los demás Religiosos de su Orden que sean Doctores en aquella Universidad; y se puede presumir, por el hecho mismo de no gloriarse delante de los jesuitas de haberse opuesto a la introducción de la dicha Teología francesa, que él y sus Hermanos la aprobasen ${ }^{96}$.

El diarista jesuita alaba el criterio unionista del maestro Alba, quien se oponía a la posible división o cisma de los agustinos calzados, favorecida por Madariaga, disgustado por haber perdido el capítulo general en 1786, pero

este maestro Alba ha sido de los principales que han sostenido la unión de la Orden y que se han opuesto a la separación del General, como él mismo se ha gloriado; y tiene justo motivo de gloriarse, porque es, sin la menor duda, un atentado muy reprensible el que los mismos Religiosos intenten esta separación y rasguen el seno de su misma Madre; [...] Y aun tiene también la satisfacción de haber vencido y haber impedido la división de su Orden ${ }^{97}$.

De estas reflexiones de Luengo, complementadas con las que había hecho en junio de $1786^{98}$, cuando fue elegido general de los agustinos calzados Stephano Bellisini, para sustituir al peruano Francisco Javier Vázquez, derrotando a otros candidatos más radicales en su antijesuitismo ${ }^{99}$ y jansenismo como Pedro Madariaga o Agustín Antonio Giorgi, surge la figura de un Alba ideológicamente más moderado, hecho confirmado con su pronto regreso a España, sin duda por no estar cómodo entre las intrigas romanas.

95. Luengo. Diario, día 23.8.1790.

96. LuENGO. Ibidem.

97. LuENGO. Ibidem

98. Luengo. Diario, día 25.6.1786.

99. Luengo. Diario, día 10.4.1777 (Tomo 11, f. 238); Fernández Arrillaga, Inmaculada. "El papel del clero en la expulsión de los jesuitas decretada por Carlos III en 1767». e.Humanista, 2014, 27, pp. 169-188. 
Luengo no parece acertado sobre el futuro cercano del maestro Alba, pues sólo escribe conjeturas que no se cumplieron, y exagera la división dentro de las órdenes religiosas españolas. Alba, lejos de estar los tres o seis años reglamentarios de su ayudantía y de aspirar a general de su orden, regresó pronto a Salamanca: «[...] y será nombrado General en el Capítulo que se debe tener en esta Ciudad de Bolonia en la primavera del año de 1792, si él quisiere serlo” ${ }^{100}$.

Lo cierto es que la orden de los agustinos calzados continuaba siendo una de la más abiertas a la cultura ilustrada y, en consecuencia, criticada por jesuitas rancios, como Luengo, como demuestra el hecho de que en 1801 el convento de Valencia comprase la Biblioteca Mayansiana, incluidos 97 libros prohibidos (157 tomos), con temas poco gratos a la ortodoxia católica, como los petrarquistas, antijesuitas, jansenistas, los contrarios a las supersticiones y al fanatismo religioso, los partidarios de la religiosidad interior y los que trataban de las corrientes jurídicas, crítico-historicistas y sociorreligiosas de la Europa más avanzada del Setecientos, sin excluir a pensamiento tan poco católico como el de Maquiavelo, el de Voltaire o el francmasón ${ }^{101}$.

No sabemos por qué la asistencia de Alba a su general duró sólo un año (había solicitado sustituto para su cátedra para un plazo de seis años, y lo normal de las asistencias eran 3 años prorrogables por otros tantos). Como hemos dicho, estuvo en Roma un año, aproximadamente desde agosto de 1790 hasta septiembre de 1791, según podemos deducir de su presencia o ausencia en los claustros salmantinos.

4.2. El jansenismo-reformismo del convento agustino en 1791: Meléndez y Jovellanos en Salamanca

Meléndez tenía derecho a participar en los claustros por su condición de doctor en Leyes, no por excatedrático de Prima de Letras Humanas. Era muy raro que un personaje, después de ascender en la carrera judicial o administrativa, retornase a la Universidad. Batilo volvió, que sepamos, en el otoño de 1791 y en 1807. Asistió a cuatro claustros plenos de la Universidad de Salamanca en octubre de 1791, al tiempo que acompañaba a Jovellanos, que estaba de visita en la ciudad de Salamanca. Por cierto, es aconsejable leerse las actas de los claustros salmantinos para interpretar correctamente lo que el gijonés escribe en su Diario por estas fechas.

Cuando en 1791 Jovellanos visita Salamanca, comisionado para programar la reforma de los Colegios de Calatrava, Santiago de los Verdes y Alcántara, alude varias veces en sus Diarios al enfrentamiento ideológico planteado en la

100. Luengo. Diario, día 23.8.1790.

101. Astorgano, Antonio. "La venta de los libros prohibidos de la Biblioteca Mayansiana (1801)». En Mestre, Antonio (coord.). Actas del Congreso Internacional sobre Gregorio Mayans. Valencia-Oliva, 6 al 8 de mayo de 1999. Valencia: Diputación Provincial, pp. 625-659. 
Universidad. Recibe Jovellanos frecuentes visitas de algunos miembros del círculo poético salmantino como Meléndez Valdés, que acude desde Valladolid, así como los PP. agustinos José Díaz y Antonio Alba, en la mañana del primer día de su llegada a Salamanca; y por la tarde del mismo día, 3 de octubre, recibió visitas de los Galianos, Salas y Forcada ${ }^{102}$. Al día siguiente recibe a miembros reformistas del claustro como Juan Justo García, Miguel Martel, Forcada, Tadeo Ortiz, y en el diario del día 13 escribe: "Por la tarde a la librería de Alegría, conversación con Salas y vuelta a casa a la oración» ${ }^{103}$.

Creemos que el flamante oidor de la Chancillería de Valladolid, Meléndez, asistió por dos motivos a los claustros de octubre de 1791: para chismear con Jovellanos los sucesos de los claustros del inicio del curso 1791-1792, que fue bastante movido, y para oponerse a la pretensión de jubilación de su viejo enemigo, el censor de la Universidad, Vicente Fernández Ocampo, cacique todopoderoso de la Facultad de Leyes, que tanto había azotado las ideas progresistas y amargado la vida a Meléndez y a sus amigos reformistas, como Ramón de Salas, quien a pesar de su brillantez tenía paralizada su vida académica en la Moderantía de Leyes y cortado el acceso a cualquier cátedra.

Meléndez estuvo presente en el claustro pleno del miércoles, 18 de octubre de 1791, que inauguraba el curso, en el que se trataron asuntos de trámite como proveer los oficios de ministros de la Universidad ${ }^{104}$. Batilo no se hizo notar en ninguna votación ${ }^{105}$. También asistió al claustro pleno del 20 de octubre de 1791, en el que se leyó una carta del Dr. D. Pedro de Acuña, futuro ministro de Gracia y Justicia con el conde de Aranda, «en que da parte a la Universidad de haberle nombrado Su Majestad consejero de Castilla» ${ }^{106}$. Después de tratar diversos asuntos, sin que conste el voto detallado de Meléndez, al final del acta nos encontramos con la firma de Meléndez en medio de la del rector y de la del secretario, lo cual no deja de ser una deferencia que, al mismo tiempo, denota que el antiguo catedrático de Letras Humanas estaba totalmente integrado en el claustro ${ }^{107}$.

Encontramos por primera vez la presencia de Alba, después de su regreso de Roma, no en el claustro pleno de inicio de curso del 18 de octubre de $1791^{108}$, sino en el del 20 del mismo mes, al que también asistieron los agustinos Pedro de Madariaga y José Díaz el doctor en Leyes Juan Meléndez Valdés, antiguo catedrático de Prima de Humanidad entre 1778 y 1789, quien llevaba dos años fuera de la Universidad, por su ascenso a magistrado. Los asuntos tratados fueron, entre

102. Jovellanos, Melchor Gaspar de. Diarios. Oviedo: Instituto de Estudios Asturianos, 1953, t. I, p. 227. Día 3 de octubre de 1791. Estudio preliminar de Ángel del Río.

103. Ibidem, p. 229. Día 13 de octubre de 1791.

104. AUSA, Libro de Claustros 249 (1790-1792), ff. 207r.-209v.

105. AUSA, Libro de Claustros 249, f. $214 \mathrm{r}$.

106. AUSA, Libro de Claustros 249, ff. 210r.-214r.

107. AUSA, Libro de Claustros 249, ff. 217r.-219r.

108. AUS, Libro de Claustros 249, ff. 207r.-210r. 
otros, el nombramiento de los oficios de la Universidad para el curso recién comenzado, entre los que le correspondió a Antonio Alba el de obrero mayor ${ }^{109}$, "por antigüedad de grado" ${ }^{110}$. Hasta entonces no encontramos el nombre de Alba en los claustros de los nueve primeros meses de 1791, faltando a casi todos los de los meses siguientes, pues el próximo claustro pleno en el que hemos registrado la presencia de Antonio Alba es el del 12 de marzo de $1792^{111}$.

Más relevancia cobrarán los claustros del 23 y 24 de octubre, porque serán citados por Jovellanos en su Diario $^{112}$, y porque trataron sobre la jubilación del poderoso doctor Vicente Fernández de Ocampo, catedrático de Prima de Leyes y censor regio. Meléndez conocía perfectamente la biografía de su principal contrincante, el doctor Ocampo ${ }^{113}$, por ser su profesor en la Facultad de Leyes en la década 1770-80 y por los enfrentamientos habidos en la siguiente ${ }^{114}$. Por su parte, Jovellanos, en el diario de los días 23 y 24, nos ha dejado una imagen negativa de Ocampo, basándose en el relato de Meléndez ${ }^{115}$ y en la visita del agustino maestro José Díaz: «Vino a verme el Maestro Fr. José Díaz y me informó del claustro. ¡Buen Dios! ¡Y lo que en él se dijo del fatuo Ocampo! ¡Y cómo le pusieron todos, todos! Se negó redondamente su solicitud, y están encargados del informe Hinojosa y Candamo» ${ }^{116}$.

Los agustinos, Meléndez y Jovellanos compartieron el regocijo ante la humillación que sufría Ocampo, negándole la jubilación anticipada ${ }^{117}$. Meléndez y la

109. El cargo de obrero mayor tenía bastante importancia, un oficio que, con el paso de los siglos, derivó en lo que hoy conocemos como un aparejador. FERNÁNDEZ Álvarez, Manuel. «1788: un año significativo en la Salamanca de la Ilustración». Studia Historica. Historia Moderna, 1990, 8, pp. 119-129.

110. AUSA, Libro de Claustros 249 (1790-1792), ff. 212v.-214r.

111. AUSA, Libro de Claustros 249, f. 319r.

112. Jovellanos. Diarios, t. I, cit., p. 232. Día 23 de octubre de 1791; Obras Completas, VI. Oviedo: Instituto Feijoo de Estudios del Siglo XvIII, 1994, p. 277.

113. Vicente Fernández de Ocampo, bachiller en Cánones en 1761, licenciado en Leyes el 25 de septiembre de 1764 y doctor en la misma facultad el 5 de noviembre de 1765 . Catedrático de Instituciones Civiles en 1770, en 1775 fue catedrático de Digesto y el 24 de agosto de 1779 pasó a ocupar la cátedra de Prima de Leyes, que desempeñó hasta que fue jubilado hacia 1799. Fue alcalde del crimen honorario de la Chancillería de Valladolid y siguió gozando de la jubilación hasta su muerte, ocurrida el 19 de marzo de 1815. EsPerabé De ArTEAGA, Enrique. Historia pragmática..., cit., vol. II, p. 732.

114. Hasta cierto punto rehabilitado en Alonso Romero, María Paz. "Ocampo y su tiempo. Biografía académica del catedrático Vicente Fernández de Ocampo (Salamanca 1743-Madrid 1815)». En Salamanca, escuela de juristas. Estudios sobre la enseñanza del derecho en el Antiguo Régimen. Madrid: Universidad Carlos III, 2012, pp. 539-638. Alonso Romero reivindica al censor Fernández Ocampo, presentándolo menos enemigo del grupo progresista-jansenista, encabezado por Meléndez Valdés y Ramón de Salas, de lo que lo había hecho Rodríguez Domínguez, Sandalio. Renacimiento universitario salmantino a fines del siglo XVIII. Ideología liberal del Dr. Ramón de Salas y Cortés. Salamanca: Universidad, 1979.

115. Jovellanos, M. G. Diarios, t. I, cit., p. 232. Día 23 de octubre de 1791.

116. Ibídem, p. 233. Día 24 de octubre de 1791

117. El claustro fue convocado en virtud de la siguiente cédula: «Para ver una Real Carta Orden del Consejo en que pide informes a la Universidad con motivo de un recurso hecho por el Sr. Dr. 
parte del claustro de tendencia reformista vieron la ocasión para resarcirse, momentáneamente, de las humillaciones que el férreo censor regio les había ocasionado desde 1784. Los ultramontanos continuaban siendo mayoría en el claustro, como se demostrará al año siguiente con el cierre del Colegio de Filosofía y la implacable persecución del reformista Ramón de Salas, pero en esta ocasión el sector ilustrado del claustro contó con la ayuda de la torpe y presuntuosa redacción de la representación elevada al Gobierno por Vicente Fernández de Ocampo, cuya lectura irritó a muchos claustrales conservadores, porque acusaba al profesorado de no saber hacer uso de su libertad («juzgan algunos con libertad para pensar a su arbitrio") $)^{118}$.

La votación del claustro estuvo presidida por el sentimiento de la Universidad de que debía "vindicar su honor con consideración a lo que expresa el Sr. Ocampo relativo a la libertad y en la defensa de conclusiones». En dicha votación se ve claramente que el todopoderoso censor regio, Fernández Ocampo, tenía demasiados enemigos y que había perdido poder durante los dos años en los que Meléndez había estado alejado de la Universidad de Salamanca, destinado como alcalde del crimen en la Real Audiencia de Aragón. Los amigos de Fernández Ocampo eran los teólogos tradicionalistas, aunque con excepciones como los reverendos José Díaz (que fue uno de los votos de referencia y esa misma tarde chismea con Jovellanos lo sucedido), Santamarina, Ridoces, Nieto, Alonso, Martel y Lecuna. No vamos a cansar al lector con la transcripción íntegra de la votación para ver la postura de cada uno de los claustrales en un tema tan delicado como el de la libertad de cátedra, que es lo que en el fondo se discutía detrás del premio al Dr. Ocampo y de la necesidad o no del mismo oficio de censor regio. El voto de Meléndez fue contundente: "Dr. Menéndez: Que la Universidad debe nombrar comisarios que desde luego se opongan con todo vigor a esta pretensión"»119.

Se observa que Meléndez dio su voto en dos veces complementarias. En la primera, simplemente se opuso "con todo vigor» a las pretensiones de Ocampo. En la segunda, tomó la palabra para apoyar la idea de su amigo el catedrático de Álgebra, el zafreño Juan Justo García, quien iba más allá de la simple denegación del cómputo de años y deseaba que el orgulloso Ocampo pidiese perdón a la Universidad por acusarla de no saber usar correctamente de la libertad de cátedra. Los catedráticos reformistas se resarcieron a su gusto de las pasadas humillaciones infringidas por el censor regio, Fernández Ocampo, el cual había ejercido una intensa actividad represora intelectualmente durante los últimos siete años (1784-1791).

Ocampo, solicitando se le conceda la gracia de que cada un biennio de los dos que ha servido y sirviere el empleo de censor regio se le compute por un año de jubilación, agregándolos a los que ha poseído y poseyere dicha cátedra para completar con todos ellos los necesarios para jubilar»..., AUSA, Libro de Claustros 249, f. 215v.

118. AUSA, Libro de Claustros 249, ff. 221r.-223v.

119. AUSA, Libro de Claustros 249, f. 223v. 
Incluso da la impresión de cierto ensañamiento de los amigos de Meléndez, pues hay peticiones bastante duras, como la del maestro Juan Justo García: "Que se nombren señores comisarios que desengañen al Dr. Ocampo de su desatino». Otros aprovechan la ocasión para pedir el cambio de censor regio, como el canonista Dr. Francisco de Paula González Candamo ("Añadiendo que se le dé a entender a Dr. Ocampo que hable con más decoro de la Universidad y que se le haga presente al Consejo que el empleo de censor regio lo servirá el más moderno de cualquiera facultad, sin interés ni ninguna preeminencia»), o simplemente su supresión, como el veterano catedrático de Cánones, Dr. D. Manuel Caballero del Pozo ("Añadió que los comisarios hagan presente al Consejo que el empleo de censor regio es superfluo en esta Universidad, mediante la obligación que tienen los decanos de revisar las conclusiones»). El voto de Meléndez fue referencia (voto de reata) para otros ocho claustrales: los doctores Mata, Cantero, Secades, Bárcena, Martel y Lecuna, y el maestro Juan Justo García.

El acuerdo del claustro coincide en lo esencial con lo propuesto por Meléndez, y recoge su expresión «oponerse con vigor»:

Concluida la votación se hizo reconocimiento de ella y salió el acuerdo de que se nombren comisarios que informen al Consejo, oponiéndose con vigor a la pretensión del Sr. Dr. Ocampo, expresando lo opuesto que es a las Constituciones y demás leyes escolásticas e intereses de la Universidad, teniendo presente lo que se ha dicho en este claustro, y que igual pretensión hizo al Consejo en los años pasados [en 1789] y se insinúe que no hay la menor necesidad de ser un censor regio en la Universidad. Y habiéndose pasado a votar los señores comisarios para el cumplimiento del acuerdo, salieron elegidos por mayor número de votos los señores doctores Candamo e Hinojosa [los cuales habían votado contrario a la pretensión del Dr. Ocampo]. Con lo cual se concluyó este claustro que firmaron dos de dichos señores. Dr. Bajo Ocerín, rector, Dr. Bárcena e yo, el secretario, en fe de ello. Ante mí, licenciado D. José Ledesma, secretario [rúbrica] ${ }^{120}$.

Meléndez y sus amigos reformistas lograron humillar al orgulloso Fernández Ocampo, para regocijo propio y del invitado Jovellanos ("se negó redondamente la solicitud del fatuo Ocampo»), como hemos visto que anotó en su Diario los días 23 y 24 de octubre de $1791^{121}$.

Los agustinos simpatizaban con Jovellanos, quien, en el plan de estudios para el Colegio de Calatrava, recomendaba a los regentes que instruyesen a sus alumnos de los errores «impíos», enseñándoles a combatirlos y reducirlos a la nada; pero de eso a que «los grandes ministros de Carlos III y IV, así como escritores, profesores universitarios y aún clérigos, eran enciclopedistas y volterianos, sin dejar de ser católicos, siendo el catolicismo la máscara y el enciclopedismo o libre

120. AUSA, Libro de Claustros 249, f. $224 \mathrm{r}$.

121. Jovellanos. Diarios, t. I, cit., p. 233. Día 24 de octubre de 1791; Obras Completas, VI, p. 277. 
pensamiento, el rostro» ${ }^{122}$, dista gran trecho, como estamos viendo en el maestro Alba.

Reintegrado a su cátedra de regencia de Teología en 1791, Alba progresivamente se convierte en la persona de más peso intelectual en el convento, pues pronto desparecerán los maestros José Díaz y Pedro Madariaga, fallecidos el 2 de febrero de 1796 y el 14 de mayo de 1797 respectivamente. Fracasados en sus aventuras romanas como asistentes del general de los agustinos Madariaga en el periodo 1780-86 y Alba en el curso 1790-91, el convento de San Agustín tuvo un trienio de cierto vigor intelectual y poético, cuando en 1791 fue nombrado prior el P. Juan Fernández de Rojas (el Liseno de la Escuela poética salmantina), pero pronto retornó a Madrid, ya que sólo estuvo en el convento el tiempo reglamentado de su priorato (1791-94). Después de la muerte de Madariaga y José Díaz, quedó Alba como principal baluarte intelectual del convento, lo que indudablemente facilitó con su amistad la tranquilidad del semidesterrado Meléndez en su retorno a Salamanca los años previos a $1808^{123}$.

Con la demolición del convento y del colegio de San Guillermo por los franceses el 17 de mayo de 1812, se cerraban casi cinco siglos de la historia del convento de los agustinos calzados salmantino, que había sido fundado en torno a 1330 y reedificado a partir de 1516, ocupando el lugar que actualmente tiene la plaza de Fray Luis de León. Con estos antecedentes es difícil creer en un sincero afrancesamiento de Antonio Alba, como vamos a ver.

\section{El AFRANCESAMIENTO DEL VICERRECTOR MAESTRO AlBA}

El maestro Alba era vicerrector con el rector Crespo Rascón (1806-1808), por lo que se vio de lleno involucrado en la reforma universitaria del ministro José Antonio Caballero (1807), antiguo alumno y condiscípulo de Meléndez Valdés.

Durante los últimos meses de 1808 Alba no apareció por los claustros de la Universidad de Salamanca. A partir del 11 de febrero de 1809, asiste con frecuencia, "haciendo de vice cancelario", y como tal votando al final las distintas cuestiones, o bien para agregar su voto a alguna de las opiniones expresadas anteriormente, o bien para sumarse al "Voto de la Universidad", cuando anteriormente una mayoría se había decantado por una decisión.

Por su talante abierto y reformista, y por su anterior vinculación con la Universidad desde 1763, era uno de los catedráticos mejor preparados para afrontar los difíciles tiempos de la Guerra de la Independencia. Así lo entendió el claustro

122. Araquistain, Luis. El pensamiento español contemporáneo. Buenos Aires: Losada, 1962, p. 15 .

123. Astorgano, Antonio. "Godoy y Meléndez Valdés en la Salamanca de 1805-1808». En Manuel Godoy y su tiempo. Congreso internacional Manuel Godoy (1767-1851). Mérida: Editora Regional de Extremadura, 2003, tomo II, pp. 161-211. 
cuando al desertar el rector, licenciado Andrés Ramos Martín, en diciembre de 1809, lo puso al frente de la Universidad, como vicerrector en funciones de rector. Tenía casi 75 años y durante más de tres años (1809-1812) dirigió la docta institución con prudencia, transigiendo en detalles menores y protocolarios con el invasor, como el nombrar doctor honoris causa al gobernador militar francés, Paul Thiébault, para evitar males mayores y aplacar su furor destructor. Es una sabia postura que adoptaron otros clérigos, como el gobernador eclesiástico de la diócesis de Teruel Juan José Alfranca y Castellote, canónigo doctoral, antiguo rector del Colegio de San Clemente de Bolonia y magistrado de la Audiencia de Extremadura ${ }^{124}$.

Este sabio posibilismo político no fue comprendido por los patriotas antifranceses del claustro, que desconfiaban de que Alba tuviese simpatía hacia los franceses. Nos surge la duda sobre su afrancesamiento ${ }^{125}$, por el hecho significativo de haber aceptado Alba un beneficio eclesiástico otorgado por el rey José I:

Por decreto de 31 de marzo de 1812 se ha dignado su magestad nombrar en encomienda para el beneficio préstamo de la iglesia del lugar de Barbadillo ${ }^{126}$, vacante por muerte de D. Josef Sánchez Velasco, a D. Antonio de Alba, ex- agustino calzado ${ }^{127}$.

Aparentemente, Alba aceptó un beneficio del francés, como Meléndez adquirió ciertas fincas rústicas desamortizadas por el mismo rey ${ }^{128}$. Para intentar aclarar la sinceridad de este afrancesamiento es necesario fijarse en las actas de los claustros universitarios del periodo 1809-1812 ${ }^{129}$, puesto que fue el máximo responsable de la Universidad desde noviembre-diciembre de $1809^{130}$ hasta su muerte en enero de 1813. No podemos detenernos en las muchas y graves dificultades derivadas del contexto bélico, que pueden aplicarse a otros notables claustrales que

124. Astorgano, Antonio. "El oidor Juan José Alfranca, visitador del Partido de Llerena en 1791". En Actas del VIII Congreso de Estudios Extremeños. Badajoz, 2007, pp. 891-932, CD; Perfil biográfico del canonista Juan Josef Alfranca y Castellote (1754-1817), rector del Colegio de Bolonia. Hispania Sacra, 2009, 123, pp. 279-352.

125. Moreno Alonso no cita al maestro Antonio José Alba, aunque alude a "Juan de Alba, ex presidente de la Religión Agustina calzada", que nada tiene que ver con el vicerrector salmantino. Cfr. Moreno Alonso, Manuel. El clero afrancesado en España. Los obispos, curas y frailes de José Bonaparte. Madrid: Biblioteca Nueva, 2014, p. 275.

126. Barbadillo es una localidad de la comarca del Campo de Salamanca (Campo Charro), situada entre Salamanca y Ciudad Rodrigo, a $22 \mathrm{~km}$ de Salamanca capital.

127. Diario de Madrid del martes 21 de abril de 1812, n. ${ }^{\circ} 112$, p. 449. No era el único exagustino calzado que aceptaba un beneficio. En el mismo Diario de Madrid (n. ${ }^{\circ}$ 132, p. 530), del 11 de mayo de 1812, fray Santiago Recio era nombrado cura vicario de Torija.

128. Astorgano. Don Juan Meléndez Valdés. El ilustrado, cit., pp. 555-556.

129. AUSA, Libros de Claustros 258 (1806-1808); Libro 259 (1808-1810); Libro 260 (Libro de Claustros y Juntas de los tres cursos desde el 10 de noviembre de 1810 hasta diciembre de 1813. Libro fundamental para nuestro estudio, pues abarca todo el rectorado en funciones del maestro Alba [noviembre de 1809-enero de 1813]); Libro 261 (1813-mayo de 1815); Libro 262 (1815-1816).

130. En el claustro pleno de 3 de noviembre de 1809 aparece la última cédula firmada por el rector Ramos, y a partir de esta fecha firma las citaciones el vicerrector Alba. 
vivieron toda la contienda sin salir de Salamanca, como Juan Justo García y Miguel Martel, más conocidos y estudiados, porque su trayectoria vital se prolongó más allá del Trienio Liberal, llegando a ser diputados en Cortes. Remitimos a la vieja y útil tesis doctoral de Florencio Amador Carrandi ${ }^{131}$.

Resumiendo, el trato asiduo del vicerrector Alba con el gobernador militar francés barón Paul Charles Thiébault (Berlín 1769-París 1846), tenido en función de su oficio y frecuentemente en compañía de un doctor abiertamente afrancesado, José Claudio Salgado, canonista y canónigo de la catedral de Salamanca, empezó a ser sospechoso para el sector patriota del claustro, de manera que la Junta universitaria que negociaba la concesión a Thiébault de los títulos de doctor (honoris causa, diríamos hoy) y de conservador de la Universidad se dividió en dos bloques, el afrancesado o mejor relacionado con el francés (Alba y Salgado) y el más patriota (el resto de la junta), que llegó a celebrar una serie de reuniones secretas, que salieron a relucir en 1815, con motivo de la visita y purificaciones que siguieron con la vuelta al absolutismo en 1814.

El catedrático José Ayuso Navarro concluye su informe sobre la conducta de la Universidad con el gobernador francés, fechado el 29 de julio de 1815, diciendo que «salió Thiébault de esta ciudad para Francia y con su salida tuvo fin este negocio, reducido a haberle entregado la Universidad, contra su voluntad, por la intriga y la fuerza, una certificación de tenerlo por su doctor honorario, sin designación de facultad, sin haberle dado insignias algunas ni asentado en sus libros» ${ }^{132}$.

Carrandi deja ciertas dudas sobre el afrancesamiento de Alba. Lo ocurrido fue efecto de la coacción militar del barón gobernador. El claustro no quería conceder el título de doctor; si lo hizo fue por evitar los grandes males que a la Universidad traería, ya que llegó a amenazar con hacerla desaparecer; por la presión de aclaustrales afrancesados, como Claudio Salgado, que apoyaba ciegamente a Thiébaul, y porque había quedado manifesto que el título de doctor que se exigía era puramente honorario y no como los que concedía la Universidad. Y aun así, parte del claustro sintió que la conciencia y la dignidad se les sublevaba y no se vio satisfecho hasta que, reunido secretamente «sin el afrancesado Salgado y el débil vicerrector Alba", manifestó la protesta contra la concesión que violentamente y contra su deseo se les arrancaba ${ }^{133}$.

Por nuestra parte, podemos deducir que si la Universidad supo resistir las presiones del general gobernador Thiébault durante tres meses (noviembre de 1811-enero de 1812), es difícil que lo pudiera hacer sin el apoyo discreto de su rector en funciones el viejo maestro Alba, quien nunca aparece en la documentación universitaria en el mismo bando claustral decididamente colaboracionista

131. AMADOR Y CARRANDI, Florencio. Investigaciones históricas: La Universidad de Salamanca en la Guerra de la Independencia. Salamanca: Universidad, 1916.

132. AUSA, Libro de Claustros 262, ff. 181v.-185v.

133. AMADOR y CARRANDI. Investigaciones históricas, cit., p. 87. 
con el invasor, capitaneado por el doctor Josef Claudio Salgado. Poco después, liberada Salamanca a consecuencia de la Batalla de los Arapiles, en julio de 1812 Alba, como rector en funciones, encabeza el juramento de la Constitución de Cádiz, leída en el claustro de 16 de dicho mes ${ }^{134}$.

Antonio Alba asiste por última vez a una junta universitaria el 2 de enero de 1813, que había convocado como claustro pleno, pero que se celebró como junta de administración "por no haberse congregado" el número suficiente (sólo 11 asistentes) para claustro. La cédula de convocatoria, firmada por Alba el viernes 1 de enero, decía: "Para oír una proposición mía [de Alba] a fin de que la Universidad nombre rector o vicerrector según sus leyes y atendiendo a mis achaques e imposibilidad ${ }^{135}$. Era la dimisión formal del agustino como vicerrector en funciones de rector. No sabemos cuándo se eligió a Salvador Texerizo como vicerrector, sustituyendo al maestro Alba (fallecido el 22 de enero). Lo cierto es que Alba ya no vuelve a aparecer en las juntas de claustros de todo el mes de febrero de 1813.

\section{Producción literaria CONSERVADa DEL MAESTRO AlBa}

Santiago Vela se limita a citar una única obra publicada conocida de Alba, $E l$ Filósofo. Oración fúnebre, que predicó, en nombre de la Universidad, a la buena memoria del franciscano observante y moderante de la Academia de Teología Fr. Manuel Fernández (1720-1772), teólogo-filósofo sin especial relevancia, a pesar del generoso apelativo que le atribuye Alba ("El filósofo") y los empleos que desempeñó dentro de su orden religiosa (custodio de su Apostólica Provincia de Santiago y guardián del Convento grande de Salamanca). Vela también subraya su colaboración con el agustino Francisco Méndez (Villaviciosa de la Alcarria, 1725-Madrid, 1803), biógrafo del P. Enrique Flórez:

Era [Alba] Maestro por la Universidad de Salamanca cuando el P. Méndez coleccionaba sus apuntes para la vida de Fr. Luis de León, y desde aquella ciudad le remitió cuantas noticias pudo encontrar referentes a la patria, estudios, empleos y escritos del insigne poeta, para lo cual llevó a cabo serias investigaciones en los archivos de la Universidad y otros centros. No agotó, sin embargo, la materia, y el trabajo del P. Méndez no debe calificarse de otro modo que de apuntes, en los cuales se encuentra el fruto de las pesquisas del P. Alba con los documentos originales que copió y las descripciones valiosas de códices que logró ver, en los que se contienen obras

134. AUSA, Libro de Claustros 260 (1810-1813), ff. 358v. y ss. Alonso Romero, María Paz. "La Universidad de Salamanca ante la Constitución de Cádiz: actitudes políticas y académicas». En AA. VV. Aulas y saberes. VI Congreso Internacional de Historia de las universidades hispánicas (Valencia, diciembre 1999). Valencia: Universitat, 2003, t. I, pp. 123-139. Reproducido en AlONSO ROMERO, María Paz. Salamanca, escuela de juristas..., cit., pp. 695-714.

135. AUSA, Libro de Claustros 260, f. 459r. 
manuscritas de Fr. Luis de León. El P. Méndez, que no pecaba de ingrato, consigna repetidísimas veces el nombre de su favorecedor P. Alba ${ }^{136}$.

Solo podemos calibrar el pensamiento y personalidad de Alba a través de tres escritos breves: dos censuras (1766 y 1778) y la citada oración fúnebre (1780). Curiosamente los tres escritos en prosa conservados de Alba tienen como referencia la vida y/o la obra de tres clérigos teólogos. El agustino, a su vez catedrático de Teología, se fija en la vertiente filosófica de los mismos. Dado el compromiso que Alba siempre manifestó con los problemas cotidianos de su universidad y su apoyo al Colegio de Filosofía impulsado por su amigo el catedrático de Matemáticas Juan Justo García, formando parte en mayo de 1788 de la comisión para organizar un colegio de filósofos y matemáticos, con el fin de elevar el nivel de las Artes, siendo uno de los que proponían la sustitución de la Física de Aristóteles por la moderna ${ }^{137}$, nos hace dudar sobre si la verdadera vocación de Alba fue la de teólogo o la de filósofo.

El único documento que tenemos para atisbar las inquietudes literarias de Alba antes de hacerse cargo de la cátedra de Prima de Humanidades (1772) es la censura, fechada el 20 de julio de 1766 y publicada al frente de un poema del helenista, y futuro inquisidor de Barcelona y Valencia, Nicolás Rodríguez Laso (1747-1820 $)^{138}$, rotulado como Poema pathético, en honra del fallecido fray Manuel Bernardo de Rivera ${ }^{139}$. Es un poema compuesto de cuarenta octavas, dedicado a las hermanas del difunto, doña Clara y doña Antonia de Rivera, religiosas trinitarias en el convento de la Villa de Villoruela.

136. Santiago Vela. Ensayo de una Biblioteca Ibero-Americana..., cit., vol. I, pp. 104-105.

137. MuÑoz Delgado, Vicente. "La Universidad de Salamanca (1778)...», cit., p. 154.

138. RoDríguez LASO, Nicolás. Diario del viage a Francia e Italia (1788). Zaragoza: Institución Fernando el Católico/Real Sociedad Económica Aragonesa de Amigos del País, 2006, pp. 24-26. Edición, prólogo y notas de Antonio Astorgano Abajo; AsTorgano, Antonio. "La personalidad del ilustrado Don Nicolás Rodríguez Laso (1747-1820), inquisidor de Barcelona y Valencia». Revista de la Inquisición de la Universidad Complutense, 1999, 8, pp. 121-187; "El Fiscal Inquisidor don Nicolás Rodríguez Laso en Barcelona (1783-1794)». Boletín de la Real Academia de Buenas Letras de Barcelona, 1999-2000, 47, pp. 197-276; “Nicolás Rodríguez Laso. Un viajero por la Europa prerrevolucionaria». Historia 16, 2002, 314, pp. 86-98; "El París del verano de 1788 a través del Diario del inquisidor Rodríguez Laso». Trienio. Revista de Ilustración y Liberalismo, 2002, 40, pp. 5-42.

139. Rodríguez Laso, Nicolás. Poema pathético que a la muerte del reverendísimo padre maestro fray Manuel Bernardo de Rivera, trinitario calzado, doctor teólogo de la Universidad de Salamanca, y su catedrático de Escoto, compuso don Nicolás Rodríguez Laso, colegial trilingüe, opositor a las cátedras de retórica de la Universidad de Salamanca y académico de honor de la Real de Buenas Letras de Sevilla, ofrécelo a las señoras doña Clara y doña Antonia de Rivera, religiosas de la orden de la Santísima Trinidad, en el convento de la Villa de Villorueda. Impreso con las licencias necesarias. Salamanca: Nicolás Villargordo y Alcaraz, 1766. Sin foliar: censura del reverendísimo padre maestro fray Antonio José de Alba, agustiniano, doctor teólogo, del gremio y claustro de la Universidad de Salamanca. Octavas en elogio del autor. 
Como dirá en 1780 en la oración fúnebre en honor del franciscano Manuel Fernández (El Filósofo), ahora el joven maestro Alba se muestra crítico con las oraciones fúnebres y les exige ser «naturales, conceptuosas, brillantes, dulces, ingeniosas":

He visto este papel que el señor juez de imprentas remite a mi censura. Ésta, a mi juicio, debe ser algo severa con semejantes obras; porque no basta que conste de los versos y pies que pide el arte, sino que se ha de dejar ver en ellas aquel numen que distingue al poeta del versista. Han de ser naturales, conceptuosas, brillantes, dulces, ingeniosas; y en fin, tales que por ella se pueda avergonzar a no sé quién, que dijo en aires de sentencia: que tanta estimación merecía un gran poeta, como un gran jugador de bolos ${ }^{140}$.

Alba simpatizaba con el joven helenista Nicolás Laso por «su gusto, su delicadeza y su numen»:

Nuestro joven don Nicolás nos da armas en su obrita para hacer ridículo este apotegma [el que comparaba al poeta con el jugador de bolos], y manifiesta su gusto, su delicadeza y su numen. Podemos esperar de estas flores frutos muy sazonados a su tiempo; y más si consideramos lo bien que le emplea en el estudio de la jurisprudencia, y lo bien impuesto que se halla en la retórica y en las lenguas más cultas, como son la francesa, italiana y, en las que ha dado a conocer su feliz estudio con la disertación que dio al público, dedicada a la Academia de Buenas Letras de Sevi$1 \mathrm{a}^{141}$, y por la que mereció ser uno de sus académicos honorarios ${ }^{142}$.

Es el único escrito que le conocemos al maestro Alba antes de hacerse cargo interinamente de la cátedra de Prima de Humanidades en noviembre de 1772 y antes de que se encontrase con Meléndez Valdés a lo largo del curso 1772-73. Alba tenía casi 38 años y Meléndez se acercaba a los 19. Cuando el extremeño llegó a Salamanca solo sabía que quería ser abogado, como su hermano Esteban (la especialización en canonista o civilista era secundaria). Ciertamente tenía inclinaciones hacia la poesía (parece que había compuesto algún poema de circunstancias en el colegio madrileño de Santo Tomás) y hacia las humanidades (estudio del griego en los Reales Estudios), pero dudamos que les diese la importancia que posteriormente tendrán en su vida, convirtiéndolas en dos auténticas "profesiones»: la de poeta y la de catedrático de humanidades (su medio de vida entre 1778 y 1789).

Estas dos "profesiones» se suscitaron en serio a partir del curso 1773-74, año en que Meléndez convivió con José de Cadalso y empezó a asistir a la cátedra de humanidades del maestro Alba y, poco después, un curso a la de griego con

140. Rodríguez Laso, Nicolás. Poema pathético..., cit.

141. RoDríguEZ LASO, Nicolás. Discurso sobre la utilidad y necesidad de la lengua griega, por Don --. Colegial Trilingüe de la Universidad de Salamanca y Profesor de Griego y Leyes en ella. Ofrécelo a la Real Academia de Buenas Letras de Sevilla. Salamanca: Nicolás Villagordo, 1765, 18 pp. 19 cm. Fue leído en la junta de dicha Academia el 22 de noviembre de 1765.

142. Rodríguez Laso, Nicolás. Poema pathético..., cit. 
el maestro fray Bernardo Zamora ${ }^{143}$. Es probable que Meléndez entablase amistad con Alba antes que con Cadalso (llegó a Salamanca en mayo de 1773).

Meléndez se encontró en 1772 con un maestro Alba, que sin ser poeta, sin embargo tenía unos profundos conocimientos de la literatura grecolatina, por razones de oficio, y suficiente criterio de la española, como para componer una censura en 1766 sobre el Poema pathético a la muerte del trinitario calzado Fr. Manuel Bernardo de Rivera.

Alba emitió un documentado dictamen en 1778 a petición del Consejo de Catilla, sobre la parte de la Lógica de los Elementa Recentioris Philosophiae (De los Elementos de Filosofía Moderna ${ }^{144}$ del oratoniano mexicano Juan Benito Díaz de Gamarra y Dávalos (Zamora, Morelia, Michoacán, 1745- San Miguel de Allende, 1783), sin duda el filósofo novohispano más representativo de la Ilustración. Poco podemos añadir al estudio específico hecho por el mercedario Vicente Muñoz Delgado $^{145}$, a donde remitimos, y a otros estudios sobre Díaz de Gamarra ${ }^{146}$.

Dado que Alba no fue un hombre del pluma y que la oración fúnebre $E l$ Filósofo es la publicación más extensa que se le conoce ${ }^{147}$, su análisis, que no podemos hacer ahora por razones de espacio, se torna imprescindible para comprender sus inclinaciones literarias y la valoración que los tres censores hacen de

143. Astorgano. Don Juan Meléndez Valdés. El ilustrado, cit., pp. 204-206.

144. DíAZ DE GAMARRA y DÁVALOS, Juan Benito. Elementa recentioris phitosophiae volumen primum Historiam philosophiae, Logicen, Metaphysicen, Ethicen atque Geometriam complectens... Volumen Alterum Physicen cum generalem tum particularem una complectens. Ex melioris notae recentioribus excerptum, congestum, adornatum. Ad usum scholaris juventutis in perillustr. Colleg. Salesiano apud PP. Presbyt. Secul. Congreg. Orat. Philipp. Michaelopolitan. In Nov. Hispan., opera et studio Johann. Benedict. Diaz de Gamarra et Davalos, eiusdem Congreg. Presb. SS. Canon. Doct. Sacrosanct. Fidei Tribunal. Commissar. ad S. Francisci Salesii Moderat. et Philosoph. Publ. Prof. Mexici, Apud Lic. D. Joseph, de Jauregui. Ann. Dni. MDCCLXXIV, 2 vols. Ha sido traducida al castellano, algunas partes repetidas veces. Elementos de filosofía moderna, t. I, presentación, trad. y notas de Bernabé Navarro (México 1963); J. Gaos con el título Tratados (México, 1947) publica Errores del entendimiento, Memorial Ajustado y Elementos de Filosofía, donde hay una selección de textos de la obra que comentamos; Elementos de filosofía moderna, volumen segundo (Antología). México: UNAM-UAEMex, 1998. Selección de Carmen Rovira y Carolina Ponce.

145. MuÑoz Delgado, Vicente. "La Universidad de Salamanca (1778)...», cit., pp. 411-462.

146. Beuchot, Mauricio. Historia de la Filosofía en el México colonial. Barcelona: Herder, 1997, pp. 241-252; CASO, A. D. "Juan Benito Díaz de Gamarra, un filósofo mexicano discípulo de Descartes». Revista de Literatura Mexicana, 1940, 2, pp. 197-213; RAmírez, A. "La lógica del Padre Díaz de Gamarra en sus Elementa". En Duc in Altum. México, 1941, pp. 79-86; Insúa RodRíGuEz, R. Historia de la filosofía en Hispanoamérica. 2. ${ }^{a}$ ed. Guayaquil: Imp. de la Universidad, 1949, pp. 192-195; GAos, José. En torno a la filosofía mexicana. México: Porrúa y Obregón, 1952; Fuentes Galindo, F. D. "Benito Díaz de Gamarra y Dávalos». En Humanidades I. México, 1963; TAPIA GARCía, M. ${ }^{a}$ V. Juan Benito Díaz de Gamarra y el modernismo en México. Tesis presentada en la Universidad Iberoamericana. México, 1966, 104 pp.; Ibargüengoitia, A. Filosofía mexicana. México, 1967, pp. 99-105. Una bibliografía completa en JunCO DE Meyer, Victoria. Gamarra o el eclecticismo en México. México: Fondo de Cultura Económica, 1973, $213 \mathrm{pp}$.

147. AlBa, Antonio José. El Filósofo..., cit. 
la misma y del agustino, cuyos méritos destacan en las disciplinas de la teología (buena elección de los temas), de las humanidades (aplicación) y de la «verdadera» filosofía, ya "bastantemente recomendado y conocido» en $1780^{148}$.

\section{Resumen. La imagen del maestro Alba Que Conoció MeléndeZ}

Desde 1764, habiendo adquirido el grado de doctor en Teología (1764), Alba tuvo pronto un lugar preeminente en el convento de Salamanca, donde permanecerá de manera ininterrumpida hasta su muerte, excepto frecuentes estancias vacacionales veraniegas en Madrid y el año largo de su asistencia al general agustino en Roma (1790-91). El curso 1772-73 es importante para Alba, pues adquiere estabilidad laboral en la Universidad con el empleo de catedrático sustituto de Prima de Humanidades en la Universidad y ocupa el tercer lugar en el rango jerárquico del convento, después de la muerte en 1770 del maestro fray Juan Manzano, catedrático de Vísperas de Teología. Antes de volver a Salamanca como prior en el curso 1775-1776, el lector (profesor) fray Diego González (Delio) ocuparía durante los cursos 1771-1773 el lugar sexto o séptimo en un hipotético escalafón jerárquico dentro del convento, pues estaba precedido por el prior, por los maestros doctores Pedro Madariaga (sustituto de la cátedra de Filosofía Moral) y Antonio Alba (sustituto de Prima de Humanidades), por el padre presentado fray Santos Mediavilla, por el padre jubilado fray Juan Díaz y por el lector fray Fernando Ayala. A su vez estaría delante del lector fray José Apraiz, del predicador fray Manuel Martín, del maestro de estudiantes fray Fernando García y del maestro de novicios padre Adrián Hernández.

Cuando Meléndez Valdés llega a Salamanca en el curso 1772-73 estaban concentrados en el convento de los agustinos los frailes que alcanzarán más renombre durante la Ilustración, como los componentes de la escuela poética fray Diego González (lector), Andrés del Corral y Juan Fernández de Rojas (estudiantes de teología). Además hallamos a fray José Antonio Díaz (amigo y confidente de Jovellanos) y fray Pedro Centeno, ambos estudiantes de teología. Lo habitual era que por unas causas u otras los frailes cambiasen de convento temporal o definitivamente. Así veremos que Andrés del Corral, según los libros de matrículas, estuvo presente en el convento desde el curso 1769-70 hasta el de 1774-75 149 , aunque

148. SÁnChez BARriga, Rafael. "Aprobación” preliminar». En Alba, Antonio José. El Filósofo..., cit., s/f.

149. Corregimos la errata de fechas introducida en nuestro estudio "Poesía y jansenismo...", p. 203 (primera línea), donde aparece sin marcar la presencia en Salamanca de Andrés del Corral en el curso 1773-74. Estuvo en Salamanca y a lo largo de ese curso debió recibir la ordenación sacerdotal. Esta errata hace confusa y errónea la frase «en el curso 1774-75 sólo aparece fray Juan Fernández de Rojas, de los ligados a la escuela poética de Salamanca» (p. 173 del citado estudio). Por lo tanto, Fernández de Rojas y Andrés del Corral permanecieron juntos en Salamanca en los cursos 1773-75, pudiendo haber conocido a José de Cadalso. 
falta en el curso 1771-72, sin que sepamos las causas. Por su parte, fray Diego González estuvo ininterrumpidamente en el convento salmantino desde el curso 1768-69 hasta el de 1778-79, con excepción de los cursos 1773-75, que anduvo inspeccionando los conventos andaluces.

Fray Juan Fernández de Rojas estará cinco cursos en Salamanca desde el de 1771-72 hasta el de 1775-76, aunque retornará como prior a principios de la década de 1790-1800, concretamente en los cursos 1791-92 al 1793-94, es decir, tres cursos, pues en el curso 1790-91 dirigía el convento el subprior Ramón Estévez ${ }^{150}$ y el 19 de diciembre de 1794, el nuevo prior fray Celedonio Urrutia matricula al colegio, continuando como subprior fray Ramón Estévez ${ }^{151}$. El 22 de noviembre de 1791 el prior fray Juan Fernández de Rojas matriculó un total de 54 frailes ${ }^{152}$. El 29 de noviembre de 1793, el mismo prior matriculó a 52 monjes $^{153}$, a los que habría que añadir a Pedro Madariaga, catedrático de Filosofía Moral, en trámites de jubilación, y Antonio José de Alba, catedrático de regencia de Teología, quienes ocupaban los números 3 y 15 en el escalafón de los doctores y catedráticos ${ }^{154}$.

Con la estancia (1780-1786) de fray Pedro de Madariaga en Roma como asistente del general agustino Francisco Javier Vázquez y la ausencia definitiva de Salamanca del prior fray Diego Tadeo González, Alba se convierte en la columna vertebral del convento salmantino. A falta de una pintura que nos muestre el retrato del agustino P. Alba (a diferencia de su amigo Juan Fernández de Rojas, que lo fue por Goya), debemos contentarnos con la imagen que conservaron de él los jesuitas desterrados que lo conocieron en Salamanca entre 1763-1767; en concreto la descripción que hace el P. Manuel Luengo (1735-1816) en 1790. Eran estrictamente coetáneos, pues ambos habían nacido en 1735 y se habían conocido en Salamanca entre 1763 y 1765 , donde el jesuita ejercía la docencia como prefecto de las conferencias escolásticas, profesor de Lógica y de Metafísica, hasta 1765 en que Luengo fue destinado a Medina del Campo y, posteriormente, a Santiago de Compostela.

La imagen que nos queda del maestro Alba es la de un reformista convencido, pero prudente y moderado, con un talante liberal enmascarado en la polémica teológica sobre el jansenismo, que no pocas veces tuvo que enfrentarse en los claustros con la intolerancia de los inmovilistas, como el premostratense Leonardo Herrero, y al final de su vida, siendo rector en funciones, con los afrancesados radicales como el doctor José Claudio Salgado.

A lo largo de los dos siglos transcurridos desde la muerte de Alba, el agustino ha ido apareciendo en escritos diversos. Lo encontramos en las listas de los ilustrados, de los reformadores, etc. Hemos descubierto pocos pormenores biográficos, y

150. AUSA, Libro de matrículas 428, f. $12 \mathrm{v}$.

151. AUSA, Libro de matrículas 502, f. $14 \mathrm{v}$.

152. AUSA, Libro de matrículas 499, f. 9r.

153. AUSA, Libro de matrículas 501, ff. 8v.-9r.

154. AUSA, Libro de matrículas 501, f. 3r. 
menos alusiones a sus aportaciones personales a los distintos campos de la cultura. Por eso, se echa en falta un estudio sintético, que abarque todo lo que, basado en esos y otros datos, pueda definir con rasgos más precisos la figura de este hombre en su peripecia vital, su obra y su pensamiento. El balance de este somero repaso nos ofrece un conocimiento de Alba reducido a unos pocos tópicos, en muchos casos muy influidos por cortapisas ideológicas, pero no existe un solo estudio sobre él; y mucho menos una obra monográfica que aborde su peripecia vital e intelectual, que fije su producción y que presente de forma sistemática su pensamiento, a partir de la lectura directa de sus escasos escritos y de la lectura pausada de los libros académicos de la Universidad de Salamanca entre 1763 y 1815.

En el presente trabajo hemos tratado de esbozar en pocas líneas los rasgos principales de la vida y personalidad del maestro Antonio Alba, sin olvidar precisar la relación amistosa e ideológica que lo unió a Meléndez Valdés, su discípulo predilecto, tanto que lo sucedió en la cátedra de Prima de Humanidades, desviando durante una larga temporada (1778-1789) su vocación de jurista, que fue la que lo había llevado a estudiar a Salamanca.

\section{APÉNDICE 155}

[Carta de Meléndez al agustino Antonio José de Alba, solicitándole información sobre su conducta, Zamora, 6 de octubre de 1801].

Mi reverendísimo padre, maestro y amigo, fray Antonio de Alba:

No extrañe Vmd. el larguísimo silencio que he guardado, porque me he propuesto ceñirme en mis correspondencias en esta obscuridad en que vivo, y además nada he tenido que decir a Vmd... Ahora le escribo para rogarle que enseguida de esta mi carta, y haciendo Vmd. cuanta memoria le sea posible, se sirva contestarme si una vez en que Vmd. vino a Medina en el tiempo de mi residencia allí, así por tener el mal gusto de verme como por ver a otros sus amigos, le acompañó en esta visita el corregidor, que entonces era, de la Villa de Madrigal, desde donde Vmd. me la hizo ${ }^{156}$, don Andrés Benito Quintana ${ }^{157}$.

155. Para contextualizar las dos cartas incluidas en este apéndice, hay que tener en cuenta que fueron redactadas cuando Meléndez empezaba su segundo destierro (el de Zamora), bastante desconcertado al principio, porque lo juzgaba inexplicable. En octubre de 1801 ya tenía claro que las causas del destierro zamorano, más penoso que el de Medina, eran las "amistades peligrosas", de personajes como el corregidor Quintana, considerado por el sector tradicionalista del clero y sociedad de Madrigal y de Ávila como cabeza de un grupo de libertinos y librepensadores. El ministro de Gracia y Justicia, José Antonio Caballero, y el partido clerical madrileño creyeron esta versión, que Meléndez desea rebatir por calumniosa, acudiendo a los testimonios favorables de todos sus amigos.

156. Antonio Alba se desplazó desde Madrigal a Medina del Campo a visitar a Meléndez.

157. Preparamos una breve biografía sobre Andrés Benito Quintana, corregidor de Madrigal de las Altas Torres y amigo de Meléndez. Era un personaje anticlerical y afrancesado bastante radical, a 
Si entrambos estuvieron vuestras mercedes hospedados en mi casa [de Medina del Campo], y qué tiempo se detuvieron [f. 61v.] en ella. Si los acompañó o no alguna otra persona de Madrigal. Si en el tiempo que vuestras mercedes se detuvieron fue mi trato con el licenciado Quintana igual al que con Vmd. tuve, franco, amistoso y sencillo; o si, por el contrario, tuvimos alguna encerrona, o nos oyó leer o hablar nada que por ningún motivo pudiese ofender a ninguna persona, aún la más delicada; y si, en fin, en aquel entonces hablamos y ofrecí yo ir al año siguiente a ver a Vmd. en el capítulo provincial de su Orden [Agustinos Calzados], que debía celebrarse en Madrigal, función muy concurrida de las gentes de aquellos pueblos, como en efecto así lo hice; y si en él vio Vmd. que me acompañaban mi mujer y el administrador de correos de Medina, expresando si hace memoria de los poquísimos días que me detuve en esta visita, pues yo la hago de haberse Vmd. quedado aún allí.

Vmd., mi antiguo y buen amigo, extrañará, sin duda, que le haga estas preguntas. En que Vmd. responda a ellas sencilla y claramente, sin disminuir ni alterar la verdad, sino diciéndola sobre su honor y su conciencia en todo y por todo, como ella es, puede ir el que un inocente repare su honor, sin que me sea dado el explicarme más. Si es posible, respóndame usted [f. 62r.] a vuelta de correo, y entre tanto mande como puede a su amigo y servidor que su mano besa. Zamora, 6 de octubre de 1801. Juan Meléndez Valdés [rúbrica]. Reverendo padre maestro fray Antonio Alba ${ }^{158}$.

[Carta del agustino Antonio José de Alba, a Meléndez, avalando su conducta, Salamanca, 9 de octubre de 1801].

Salamanca y octubre, 9 de 1801.

Muy señor mío y amigo:

En esta ciudad [Salamanca] se dijo que estaba Vmd. en Zamora ${ }^{159}$, y ahora lo veo por la que Vmd. me escribe, después de dos años que no me ha contestado Vmd. a un empeño que hice por mi criado $^{160}$. Esta pereza de Vmd. me tenía algo mohíno y no respondiera a la de hoy de Vmd., a no ser por lo que Vmd. me dice de poder salvar un inocente.

Yo no lo entiendo. Se me ha figurado si con la soledad y sus trabajos se ha hecho Vmd escrupuloso y quiere hacer alguna confesión general menudísima.

quien Leandro Fernández de Moratín no dudará en calificar de «imprudente» en 1818.

158. RAE, RM, Caja 61/2, pieza 11, ff. 61r.-62r. Original autógrafo en RAE, RM, Caja 61/2, pieza 19, ff. $103 \mathrm{r}-104 \mathrm{v}$.

159. Alba seguía los avatares de Meléndez, quien llevaba en Zamora desde el 16 de abril, es decir, menos de seis meses.

160. Se deduce que desde finales de 1799 Meléndez se sentía observado por sus enemigos y adoptaba ciertas medidas de discreción, como evitar la correspondencia con su maestro fray Antonio Alba. 
Hará Vmd. bien y voy a decir a Vmd. sobre sus preguntas y viaje, aunque en él no vi ni oí cosa en que Vmd. pecase.

Me hallaba en Madrigal a visitar las monjas, y me acordé que Vmd. estaba en Medina y que no había visto bien el excelente cuadro que hay en el claustro del convento de mi orden. Díjele al corregidor de Madrigal, Quintana, que pensaba en ir a Medina a ver a Vmd., y el dicho [f. 62v.] cuadro, pues yo iré también gustoso -me dijo-. Bien, pues pediré a las monjas el birlocho. Con efecto le pedí y fuimos juntos, y he respondido a la primera pregunta.

A la segunda, [respondo] que los dos fuimos a apearnos a su casa de Vmd., donde estuvimos día y medio. Porque las monjas necesitaban el birlocho, no me detuve más. Nadie vino con nosotros de Madrigal.

A la tercera [pregunta] digo que yo no noté que Vmd. tuviese otro trato con el corregidor que el que tenía conmigo, ni yo le hubiera sufrido. Tampoco vi ni hubo tiempo para encerrona ${ }^{161}$, como Vmd. dice, ni sé para qué había de haber esta encerrona, y faltarme a mí al obsequio que merecía mi visita.

A la cuarta, digo que ni oí hablar ni leer a Vmd. ni al corregidor cosa que pudiese ofender a persona bien criada, ni tampoco yo lo hubiera permitido, usando de mi estado, carácter y edad.

A la quinta (sic cuarta) digo que yo le ponderé a Vmd. la función del capítulo [provincial de los agustinos calzados], con motivo de que me pagase la visita, y mucho más porque se deleitase con las bellas pinturas que hay en mí convento de los famosos pintores. Que concurrió Vmd. con su [f. 63r.] parienta y el corregidor de Medina, digo el administrador de $\operatorname{correos}^{162}$, como concurren todos los lugares de la comarca. Que estuvo Vmd. en Madrigal no me acuerdo qué días. Que se fue Vmd. dejándome a mí allí asistiendo a las funciones capitulares que restaban y eran ocultas, porque sólo concurrían a ellas los padres del definitorio ${ }^{163}$. Que no he vuelto a saber de Vmd. desde entonces, porque no me ha escrito.

Quisiera acordarme de todo lo que hablamos y oí hablar para satisfacer abundantemente a su curiosidad y escrupulosidad de usted, pero no tengo tanta memoria. Sólo me acuerdo, en general, de los capítulos, de las conversaciones [con Meléndez], que fueron del plantío que hizo el corregidor, de la Colegiata en

161. Subrayado en el original.

162. Inmediatamente después de llegar desterrado a Medina del Campo, se formó en torno a Meléndez un círculo de amigos, compuesto por las personas más notables e ilustradas de la villa, encabezadas por el corregidor, don Justo Martínez de Baños, y por don Lucas Escribano, «administrador principal de postas, caminos y correos de la Villa de Medina y su departamento, vecino de ellan, a quien el poeta le encargará en lo sucesivo la compra de libros. Su hijo era el abogado don Jerónimo Escribano y Montoya. Los dos declararán a favor de la inocencia de Meléndez en el otoño de 1801, igual que el maestro Alba (A. H. de Protocolos de Valladolid, Leg. 6810, f. 160-173. Cfr. Demerson: Don Juan, I, pp. 355 y ss.

163. Definitorio: Cuerpo que, con el general o provincial de una orden, componen para regirla los definidores generales o provinciales. 
Medina, del célebre cuadro ya dicho, del edificio de cuarteles ${ }^{164}$, y del destino que Vmd. allí tenía. Yo acompañé a usted a casa del corregidor y vuestras Mercedes me acompañaron, a lo menos usted, a unas monjas, porque Quintana fue a comprar no sé qué cosas.

Todo esto lo digo con la verdad que es mi carácter y corresponde a mi estado. Vea Vmd. si tiene más que preguntar [f. 63v.], pero no me obligue Vmd. a escribir a vuelta de correo y en sus cartas, porque no estoy tan de vagar, ni mi letra es para estas estrecheces ${ }^{165}$. Memorias a mi señora doña Andrea y mande Vmd. a su amigo. Fray Antonio Alba ${ }^{166}$.

\section{BIBLIOGRAFÍA}

Alba, Antonio José de. El Filósofo. Oración fúnebre. Salamanca: Oficina de la Santa Cruz, s. a. [¿1780?]. http://bdh-rd.bne.es/viewer.vm?id=0000085728\&page=1.

Alonso Romero, María Paz. "La Universidad de Salamanca ante la Constitución de Cádiz: actitudes políticas y académicas». En Aulas y saberes. VI Congreso Internacional de Historia de las universidades hispánicas (Valencia, diciembre 1999). Valencia: Universitat, 2003, t. I, pp. 123-139.

Alonso Romero, María Paz. «Ocampo y su tiempo. Biografía académica del catedrático Vicente Fernández de Ocampo (Salamanca 1743-Madrid 1815)». En Salamanca, escuela de juristas. Estudios sobre la enseñanza del derecho en el Antiguo Régimen. Madrid: Universidad Carlos III, 2012, pp. 539-638.

AMADOR Y CARRANDI, Florencio. Investigaciones históricas: La Universidad de Salamanca en la Guerra de la Independencia. Salamanca: Universidad, 1916.

ARAQUISTAIN, Luis. El pensamiento español contemporáneo. Buenos Aires: Losada, 1962.

Archivo de la Universidad de Salamanca, Libro Procesos de cátedras 1016-1017; Libro de Claustros 242-243, 248-249, 258-262; Libro de matrículas 254, 428, 490-506, 508-516.

Archivo Histórico de Loyola, Escritos de jesuitas del XVIII. Manuel Luengo. Diario de la expulsión de los jesuitas de los dominios del rey de España, 49 vols.

Archivo Histórico Diocesano de Madrid, Parroquia de Santa Cruz, Libro de bautismos 25 (1729-1736).

Archivo Histórico Nacional, Códices y Cartularios, Libro VI de profesiones del convento de agustinos ermitaños de San Felipe el Real de Madrid, Códice L. 206; Consejos, legajo 6011, expediente 108; Consejos, legajo 6024, expediente 97.

Archivo Histórico de Protocolos de Valladolid, legajo 6814.

Astorgano, Antonio. "La venta de los libros prohibidos de la Biblioteca Mayansiana (1801)». En Mestre, Antonio (coord.). Actas del Congreso Internacional sobre Gregorio Mayans,

164. El ministro José Antonio Caballero firmó la orden de destierro de agosto de 1798, encubriéndolo bajo la comisión de que Meléndez inspeccionase los cuarteles de Medina.

165. En efecto parte de la carta de la respuesta del P. Alba está escrita en los márgenes de la de Meléndez.

166. RAE, RM, Caja 61/2, pieza 11, ff. 62r.-63v. Original autógrafo en RAE, RM, Caja 61/2, pieza 19, ff. 105r.-106r. 
APROXIMACIÓN AL AGUSTINO FRAY ANTONIO JOSÉ DE ALBA (1735-1813), MAESTRO DE MÉLENDEZ VALDÉS

Valencia-Oliva, 6 al 8 de mayo de 1999. Valencia: Diputación Provincial, 1999, pp. 625-659.

Astorgano, Antonio. «La personalidad del ilustrado Don Nicolás Rodríguez Laso (1747-1820), inquisidor de Barcelona y Valencia». Revista de la Inquisición, 1999, 8, pp. 121-187.

Astorgano, Antonio. "El paso de Jovellanos y Meléndez Valdés por el Ministerio de Gracia y Justicia (1798)». Revista de Estudios Extremeños, 1999, 55-3, pp. 995-1052.

Astorgano, Antonio. «El Fiscal Inquisidor don Nicolás Rodríguez Laso en Barcelona (17831794)». Boletín de la Real Academia de Buenas Letras de Barcelona, 1999-2000, 47, pp. 197-276.

Astorgano, Antonio. «Nicolás Rodríguez Laso. Un viajero por la Europa prerrevolucionaria». Historia 16, 2002, 314, pp. 86-98.

Astorgano, Antonio. "El París del verano de 1788 a través del Diario del inquisidor Rodríguez Laso». Trienio. Revista de Ilustración y Liberalismo, 2002, 40, pp. 5-42.

Astorgano, Antonio. "Godoy y Meléndez Valdés en la Salamanca de 1805-1808». En Manuel Godoy y su tiempo. Congreso internacional Manuel Godoy (1767-1851). Mérida: Editora Regional de Extremadura, 2003, II, pp. 161-211.

Astorgano, Antonio. Don Juan Meléndez Valdés. El Ilustrado. Badajoz: Diputación Provincial, 2007.

Astorgano, Antonio. «El oidor Juan José Alfranca, visitador del Partido de Llerena en 1791». En Actas del VIII Congreso de Estudios Extremeños. Badajoz, 2007, pp. 891-932. CD-ROM.

Astorgano, Antonio. «Perfil biográfico del canonista Juan Josef Alfranca y Castellote (17541817), rector del Colegio de Bolonia». Hispania Sacra, 2009, 123, pp. 279-352.

Astorgano, Antonio. "Poesía y jansenismo en el convento de los agustinos calzados de Salamanca en tiempos de Meléndez Valdés». Revista de Estudios Extremeños, 2016, 77.1, pp. 147-208.

Beuchot, Mauricio. Historia de la Filosofía en el México colonial. Barcelona: Herder, 1997.

Caso, A. D. "Juan Benito Díaz de Gamarra, un filósofo mexicano discípulo de Descartes». Revista de Literatura Mexicana, 1940, 2, pp. 197-213

Demerson, Georges. Don Juan Meléndez Valdés y su tiempo 1754-1817. Madrid: Taurus, 1971.

Diario de Madrid, 21 de abril de 1812, 11 de mayo de 1812.

Díaz de Gamarra y DÁvalos, Juan Benito. Elementos de filosofía moderna, T. I. Ed. Bernabé Navarro. México, 1963.

DíAZ DE GAMARRA y DÁvalos, Juan Benito. Elementa recentioris philosophiae volumen primum. México: Joseph de Jauregui, 1774.

Díaz de Gamarra y Dávalos, Juan Benito. Tratados. Ed. J. Gaos, México, 1947.

Díaz de Gamarra y Dávalos, Juan Benito. En Elementos de filosofía moderna. Antología. Ed. Carmen Rovira y Carolina Ponce. México: UNAM-UAEMex, 1998.

Domínguez Carretero, Eloy. "La escuela teológica agustiniana de Salamanca». La Ciudad de Dios, Revista Agustiniana, 1956, 168, pp. 638-685.

Esperabé de ARTEAga, Enrique. Historia pragmática e interna de la Universidad de Salamanca. Salamanca: Imprenta y Librería de Francisco Núñez, 1917, vol. II.

FERnÁNDEZ Álvarez, Manuel. «1788: un año significativo en la Salamanca de la Ilustración». Studia Historica. Historia Moderna, 1990, 8, pp. 119-129.

FERNÁNDEZ ARRILlaga, Inmaculada. "El papel del clero en la expulsión de los jesuitas decretada por Carlos III en 1767». e.Humanista, 2014, 27, pp. 169-188. 
Fuentes Galindo, F. D. «Benito Díaz de Gamarra y Dávalos». En Humanidades I. México, 1963. Gaos, José. En torno a la filosofía mexicana. México: Porrúa y Obregón, 1952.

Guitarte IzQuierdo, Vidal. Episcopologio Español (1700-1867). Castellón de la Plana: Ayuntamiento, 1992.

Ibargüengoitia, A. Filosofía Mexicana. México: Porrúa, 1967.

Insúa RODRíGueZ, R. Historia de la filosofía en Hispanoamérica. 2. ${ }^{a}$ ed. Guayaquil: Imp. de la Universidad, 1949.

Jovellanos, Gaspar Melchor de. Diarios. Oviedo: Instituto de Estudios Asturianos, 1953, t. I.

Jovellanos, Gaspar Melchor de. Diarios, t. I. Obras Completas, VI. Oviedo: Instituto Feijoo de Estudios del Siglo XVIII, 1994.

Junco De Meyer, Victoria. Gamarra o el eclecticismo en México. México: Fondo de Cultura Económica, 1973.

Luengo, Manuel. Diario de la expulsión de los jesuitas de los dominios del rey de España... Archivo Histórico de Loyola, Escritos de jesuitas del XVIII, 49 vols.

MarTíneZ, Agustín M. Introducción a la teología del cardenal Enrique Noris, agustino (1631-1704). Santiago de Chile: Imp. Lathrop, 1946.

MuÑoz Delgado, Vicente. «La Universidad de Salamanca (1778) y los "Elementa recentioris Philosophiae" (México 1774) de Juan Benito Díaz de Gamarra y Dávalos». Cuadernos Salmantinos de Filosofía, 1981, 8, pp. 149-174.

MuÑoz Delgado, Vicente. "Los agustinos y la Filosofía en México durante el siglo XVI». Ciudad de Dios: Revista Agustiniana, 1992, 205, 2-3, pp. 411-462.

Nicole, Pierre y ARnauld, Antoine. La logique ou L'art de penser. París: G. Desprez, 1683.

Ramírez, A. "La lógica del Padre Díaz de Gamarra en sus Elementa». En Duc in Altum. México, 1941, pp. 79-86.

Robledo, Ricardo. "Juan Justo García». En Lama, José María (ed.). Los primeros liberales españoles. La aportación de Extremadura, 1810-1854. Badajoz: Diputación Provincial de Badajoz, 2012, pp. 27-48.

Rodríguez Domínguez, Sandalio. Renacimiento universitario salmantino a fines del siglo XVIII. Ideología liberal del Dr. Ramón de Salas y Cortés. Salamanca: Universidad, 1979.

RODRíguez Laso, Nicolás. Discurso sobre la utilidad y necesidad de la lengua griega. Salamanca: Nicolás Villagordo, 1765.

Rodríguez Laso, Nicolás. Poema pathético que a la muerte del reverendísimo padre maestro fray Manuel Bernardo de Rivera. Salamanca: Nicolás Villagordo y Alcaraz, 1766.

Rodríguez Laso, Nicolás. Diario del viage a Francia e Italia (1788). Ed. Antonio Astorgano Abajo. Zaragoza: Institución Fernando el Católico-Real Sociedad Económica Aragonesa de Amigos del País, 2006.

Santiago Vela, Gregorio de. Ensayo de una Biblioteca Ibero-Americana de la Orden de San Agustín. vol. I, letras A-Ce. Madrid: Imprenta del Asilo de Huérfanos del Sagrado Corazón de Jesús, 1915.

Simón ReY, Daniel. Las facultades de Artes y Teología de la Universidad de Salamanca en el siglo XVIII. Salamanca: Universidad, 1981.

Tapia García, M. ${ }^{a}$ V. Juan Benito Díaz de Gamarra y el modernismo en México. Tesis presentada en la Universidad Iberoamericana. México, 1966.

WerniCKE, Michael Klaus. Kardinal Enrico Noris und siene Verteidigung Augustins. Würzburg: Augustinus-Verlag, 1973.

ZAONERO, Joaquín. Libro de noticias de Salamanca que empieza a regir el año de 1796 hasta 1812. Ed. Ricardo Robledo. Salamanca: Librería Cervantes, 1998. 